Discussion Paper No. 800

\title{
THE WELFARE EFFECTS \\ OF THIRD-DEGREE \\ PRICE DISCRIMINATION \\ IN A DIFFERENTIATED OLIGOPOLY
}

\author{
Takanori Adachi \\ Noriaki Matsushima
}

January 2011

The Institute of Social and Economic Research

Osaka University

6-1 Mihogaoka, Ibaraki, Osaka 567-0047, Japan 


\title{
The Welfare Effects of Third-Degree Price Discrimination in a Differentiated Oligopoly*
}

\author{
TAKanori AdACHi ${ }^{\dagger} \quad$ Noriaki Matsushima ${ }^{\ddagger}$
}

January 17, 2011

\begin{abstract}
This paper studies the relationship between horizontal product differentiation and the welfare effects of third-degree price discrimination in oligopoly. By deriving linear demand from a representative consumer's utility and focusing on the symmetric equilibrium of a pricing game, we characterize the conditions relating to such demand properties as substitutability and complementarity for price discrimination to improve social welfare. In particular, we show that price discrimination can improve social welfare if firms' brands are substitutes in a market where the discriminatory price is higher and complements in one where it is lower, but welfare never improves in the reverse situation. We verify, however, that consumer surplus is never improved by price discrimination; welfare improvement by price discrimination is solely due to an increase in the firms' profits. This means that there is no chance that firms suffer from a "prisoners' dilemma," that is, firms are better off by switching from uniform pricing to price discrimination.
\end{abstract}

Keywords: Third-Degree Price Discrimination; Oligopoly; Social Welfare; Horizontal Product Differentiation; Substitutability; Complementarity.

JEL classification: D43, D60, L11, L13.

${ }^{*}$ We are grateful to Hiroaki Ino and seminar participants at Kwansei Gakuin University and the University of Tokyo for helpful comments. Adachi also acknowledges a Grant-in-Aid for Young Scientists (B) from the Japanese Ministry of Education, Science, Sports, and Culture (21730184). Matsushima acknowledges a Grant-in-Aid for Scientific Research (B) from the Ministry (21730193). Any remaining errors are our own.

${ }^{\dagger}$ School of Economics, Nagoya University, Chikusa, Nagoya 464-8601, Japan. E-mail: adachi.t@soec.nagoya-u.ac.jp

${ }^{\ddagger}$ Institute of Social and Economic Research, Osaka University, 6-1 Mihogaoka, Ibaraki, Osaka 567-0047, Japan. E-mail: nmatsush@iser.osaka-u.ac.jp 


\section{Introduction}

Product differentiation is one of the main reasons why firms can enjoy market power; it enables them to sell products that are no longer perfect substitutes. For example, Coca Cola and PepsiCo sell similar types of soda, though it is arguable that they differ in taste. Each firm thereby attracts some consumers over another. It is often the case that firms' differentiation of their products leads consumers to value the variety. Examples of complementary products abound and include such products as beer and breakfast cereal.

If firms have some control over the price that consumers pay, they naturally want to take advantage of it. Third-degree price discrimination is one marketing technique that is widely used in imperfectly competitive markets. In third-degree price discrimination, the seller uses identifiable signals (e.g., age, gender, location, and time of use) to categorize buyers into different segments or submarkets, each of which is given a constant price per unit. Behind the recent trend toward third-degree price discrimination is rapid progress in information-processing technology, notably including the widespread use of the Internet in the past two decades. ${ }^{1}$

This paper examines the welfare effects of oligopolistic third-degree price discrimination, explicitly considering product differentiation as a source of market power and strategic interaction. In a story related to the example in the first paragraph, the New York Times once reported (October 28, 1999) ${ }^{2}$ that Coca Cola was testing a vending machine that would automatically raise prices in hot weather. Although the article triggered nationwide controversy and Coca Cola had to abandon the project as a result, the plan could have changed the regime of uniform pricing to one of regional price discrimination in the soda market. How would the resulting change affect consumer welfare and firms' profits? In other words, is third-degree price discrimination is good or bad? Answering this question is important because it helps antitrust authorities to evaluate price discrimination in two important characteristics of market: oligopoly and product differentiation.

In this paper, we focus on horizontal product differentiation to consider substitutability

\footnotetext{
${ }^{1}$ See Shy (2008) concerning how advances in the information technology have made 'fine-tailored' pricing tactics more practicable for sellers.

${ }^{2}$ http://www.nytimes.com/1999/10/28/business/variable-price-coke-machine-being-tested.html (retrived January 2011)
} 
as well as complementarity. ${ }^{3}$ By deriving linear demand from a representative consumer's utility and focusing on the symmetric equilibrium of a pricing game, we characterize the conditions relating to such demand properties as substitutability and complementarity required for price discrimination to improve social welfare. In particular, we show that price discrimination can improve social welfare (especially) if brands are substitutes in a market where the discriminatory price is higher and complements in the market where it is lower, but never when the reverse situation holds. We verify, however, that consumer surplus is never improved by price discrimination: welfare improvement from price discrimination is solely due to an increase in firms' profits. This means that there is no chance that firms suffer from "prisoners' dilemma,"; that is, films are better off switching from uniform pricing to price discrimination.

Since Pigou's (1920) seminal work, the central question in the analysis of third-degree price discrimination is about its welfare effects: what are the effects of third-degree price discrimination on consumer surplus and Marshallian social welfare (the sum of consumer surplus and firms' profits)? In the literature, however, little has been reported about the welfare effects of oligopolistic third-degree price discrimination since the publication of a seminal paper by Holmes (1989), which analyzes the output effects of third-degree price discrimination in oligopoly, but not the welfare effects. ${ }^{4}$ On the other hand, the welfare effects of monopolistic third-degree price discrimination are relatively well known. Since the work by Robinson (1933), it has been well known that when all submarkets are served under uniform pricing, ${ }^{5}$ price discrimination must decrease social welfare unless aggregate output increases. This implies that an increase in aggregate output is a necessary condition

\footnotetext{
${ }^{3}$ With horizontal product differentiation, some consumers prefer product $A$ to $B$ while others prefer $B$ to $A$. On the other hand, vertical product differentiation captures the situation where all consumers agree on the ranking of products. See, for example, Belleflamme and Peitz (2010, Ch.5) for further discussion of its distinction.

${ }^{4}$ See Armstrong (2006) and Stole (2007) for comprehensive surveys of price discrimination with imperfect competition. In contrast to Holmes' (1989) focus on a symmetric Nash equilibrium (where all firms behave identically), an important work by Corts (1998) relaxes the requirement for symmetry to show that asymmetry in firms' best response functions is necessary for unambiguous welfare effects (when prices drop in all markets, the result is unambiguous welfare improvement, and when these prices jump, the result is unambiguous welfare deterioration). Our focus on a symmetric equilibrium is based on the assumption that all firms agree in their ranking in pricing (see Stole (2008) for details), and is motivated by our recognition that this situation is more natural than the asymmetric cases in many examples of third-price discrimination.

${ }^{5}$ Under uniform pricing, firms may be better off by refusing supply to some submarkets. See, for example, Hausman and MacKie-Mason (1988) regarding this issue.
} 
for social welfare to be improved by third-degree price discrimination. ${ }^{6}$ In particular, price discrimination necessarily decreases social welfare if demands are linear because aggregate output remains constant. ${ }^{7}$ The welfare consequences of oligopolistic third-degree price discrimination, however, remain largely unknown. It is therefore important to study oligopolistic third-degree price discrimination, because only a small number of goods are supplied by monopolists in the real world and an increasing number of firms use price discrimination for their products and services.

This paper investigates the relationship between product differentiation and change in social welfare associated with the regime change from uniform pricing to price discrimination when all submarkets are open under uniform pricing. ${ }^{8}$ To model price competition with product differentiation, we adopt the Chamberlin-Robinson approach (named by Vives (1999, p.243)): a "representative" consumer (i.e., a virtual individual that is an aggregation of an infinitesimal number of identical consumers) is assumed to value the variety of goods. In this paper, we consider the (fully parameterized) linear demand structure to obtain an explicit solution as well as an explicit condition for all submarkets to be open under uniform pricing. The benefit of this specification is that we do not have to simply assume such endogenous events as a market opening. In addition, while Holmes (1989) assumes substitutability of products, our formulation allows inclusion of complementarity in a welfare analysis.

One important difference between monopoly and oligopoly is that in a monopoly, the price elasticity of demand in each submarket has a one-to-one relationship with the optimal discriminatory price: the larger the price elasticity, the lower the discriminatory price is. In oligopoly, however, this may not be the case because strategic interaction affects the

\footnotetext{
${ }^{6}$ Aguirre, Cowan, and Vickers (2010) offer a comprehensive analysis, finding sufficient conditions relating the curvatures of direct and indirect demand functions in separate markets. While they allow nonlinear demand functions, they, like many researchers, restrict an endogenous event: all markets are simply assumed to be open. Cowan (2007) offers a similar analysis by restricting a class of demand functions.

${ }^{7}$ For example, Schamalensee (1981), Varian (1985), Schwartz (1990), and Bertoletti (2004). In contrast to these studies, Adachi $(2002,2005)$ shows that, when there are consumption externalities, price discrimination can increase social welfare even if aggregate output remains the same (see Ikeda and Nariu (2009)). Ikeda and Toshimitsu (2010) show that if quality is endogenously chosen, price discrimination necessarily improves social welfare.

${ }^{8}$ In a similar study, Dastidar (2006) considers the welfare effects of third-degree price discrimination in oligopoly by focusing on symmetric Nash equilibrium, as this paper does. In comparison to Dastidar's (2006) study, ours explicitly takes into account such demand properties as substitutability and complementarity to characterize the conditions under which price discrimination improves social welfare.
} 
pricing decision of each firm. In particular, the price elasticity that a firm faces in a discriminatory market is generally different from the elasticity that the firms as a whole (i.e., in a collusive oligopoly) face. In this paper, we show that in equilibrium this "firmlevel" price elasticity has a simple expression in terms of product differentiation. More specifically, it is verified that, as in Holmes (1989), in equilibrium the firm-level price elasticity decomposes into "market-level" and "strategic-related" elasticity (the precise meanings are given in the text). The latter elasticity simply coincides with the degree of product differentiation. ${ }^{9}$ It is observed from numerical and graphical analysis that this "strategic" elasticity plays an important role in the determination of discriminatory prices and social welfare. One benefit of using linear demands is that we can evaluate welfare without the complications associated with demand concavity/convexity.

The rest of the paper is organized as follows. The next section presents a model and preliminary results. Section 3 presents the welfare analysis. Section 4 concludes the paper. Technical arguments are relegated to the Appendix.

\section{The Model}

In this section, we first set up the model and then provide the preliminary results necessary for the welfare analysis in the next section.

\subsection{Setup}

Firms produce (horizontally) differentiated products and compete in price to sell their products (directly) to consumers. A firm sells only one type of product, which can therefore also be interpreted as a brand. Markets are partitioned according to identifiable signals (e.g., age, gender, location, and time of use). ${ }^{10}$ The qualifier "horizontally" denotes that firms differentiate by targeting consumer heterogeneity in taste rather than quality. For simplicity, we assume that all firms have the same constant marginal cost, $c \geq 0$. Resale among consumers must be impossible, otherwise some consumers would be better off

\footnotetext{
${ }^{9}$ Our analysis below shows that Holmes' (1989) decomposition also holds for the case of complementarity with linear demands in the specification of our paper.

${ }^{10}$ There are no interdependencies between separate markets. Layson (1998) and Adachi (2002) study the welfare effects of monopolistic third-degree price discrimination in the presence of interdependencies.
} 
buying the good at a lower price from other consumers (arbitrage).

Following Robinson (1933) and most subsequent papers in the literature, we suppose that the whole market is divided into two subgroups: "strong" and "weak" markets. Loosely put, a strong (weak) market is a "larger" ("smaller") market. ${ }^{11}$ Consumer preference in market $m \in\{s, w\}$ ( $s$ denotes (the set of) the strong markets and $w$ the weak markets) is represented by the following quasi-linear utility function:

$$
U_{m}\left(q_{m}^{A}, q_{m}^{B}\right) \equiv \alpha_{m} \cdot\left(q_{m}^{A}+q_{m}^{B}\right)-\frac{1}{2}\left(\beta_{m}\left[q_{m}^{A}\right]^{2}+2 \gamma_{m} q_{m}^{A} q_{m}^{B}+\beta_{m}\left[q_{m}^{B}\right]^{2}\right)
$$

where $\left|\gamma_{m}\right|<\beta_{m}$ denotes the degree of horizontal product differentiation in market $m$, $q_{m}^{j}$ is the amount of consumption/output produced by firm $j$ for market $m(j \in\{A, B\})$, and $\beta_{m}>0 .{ }^{12}$ Notice that this specification allows the cross-partial derivative to be expressed by just one parameter: $\partial U_{m} / \partial q_{m}^{A} \partial q_{m}^{B}=-\gamma_{m}$. If $\gamma_{m}>0$, the goods in market $m$ are called substitutes. On the other hand, they are called complements if $\gamma_{m}<0$. If $\gamma_{m}=0$, they are independent. Notice that the direction of the sign is associated with the usual definitions of complementarity/substitutability: when the firms' goods are substitutes (complements), the marginal utility from consuming an additional unit of the good purchased from one firm is lower (higher) when a consumer consumes more units of the good from the other firms. Note that the lower the value of $\gamma_{m}$, the more differentiated firms' products are. ${ }^{13}$ The ratio $\gamma_{m} / \beta_{m} \in(-1,1)$ is interpreted as a (normalized) measure of horizontal product differentiation in market $m$ (see Belleflamme and Peitz (2010, p.65)). As we see in Section $3, \gamma_{m} / \beta_{m}$ plays an important role in interpreting the equilibrium prices under price discrimination.

Utility maximization by the representative consumer yields the inverse demand function for firm $j$ in each market $m, p_{m}^{j}\left(q_{m}^{j}, q_{m}^{-j}\right)=\alpha_{m}-\beta_{m} q_{m}^{j}-\gamma_{m} q_{m}^{-j}$. The demand

\footnotetext{
${ }^{11}$ More precisely, following the literature, we define a strong (weak) market as one in which the price is increased (decreased) by price discrimination. Notice that this definition is based on an "equilibrium" result from optimizing behavior (either in monopoly or oligopolistic pricing). Appendices A1 and A2 show the parametric restrictions by which a market is strong or weak in the model presented below.

${ }^{12}$ More precisely, we assume that the utility function has a quasi-linear form of $U_{m}\left(q_{m}^{A}, q_{m}^{B}\right)+q_{0}$, where $q_{0}$ is the "composite" good (produced by the competitive sector) whose (competitive) price is normalized at one. Thus, there are no income effects on the determination of demands in the markets that are focused, validating partial equilibrium analysis. This quadratic utility function is a standard one that justifies linear demands (see Vives (1999, p.145), for example). Here, symmetry between firms is additionally imposed.

${ }^{13}$ In the case of independence in market $m\left(\gamma_{m}=0\right)$, each firm behaves as a monopolist of its own brand. Hence, the results from studies of monopolistic third-degree price discrimination with linear demands apply.
} 
functions in market $m$ are thus given by

$$
\left\{\begin{array}{l}
q_{m}^{A}\left(p_{m}^{A}, p_{m}^{B}\right)=\frac{\alpha_{m}}{\beta_{m}+\gamma_{m}}-\frac{\beta_{m}}{\beta_{m}^{2}-\gamma_{m}^{2}} p_{m}^{A}+\frac{\gamma_{m}}{\beta_{m}^{2}-\gamma_{m}^{2}} p_{m}^{B} \\
q_{m}^{B}\left(p_{m}^{A}, p_{m}^{B}\right)=\frac{\alpha_{m}}{\beta_{m}+\gamma_{m}}+\frac{\gamma_{m}}{\beta_{m}^{2}-\gamma_{m}^{2}} p_{m}^{A}-\frac{\beta_{m}}{\beta_{m}^{2}-\gamma_{m}^{2}} p_{m}^{B}
\end{array}\right.
$$

Notice here that the symmetry in firms' demands, $q_{m}^{A}\left(p^{\prime}, p^{\prime \prime}\right)=q_{m}^{B}\left(p^{\prime \prime}, p^{\prime}\right)$. As stated above, we follow Holmes (1989) and many others to focus on a symmetric Nash equilibrium where all firms set the same price in one market. ${ }^{14}$ With little abuse of notation, let $q_{m}(p)=q_{m}^{A}(p, p)$. For a simpler exposition, there are two firms and two discriminatory markets. These numbers can be arbitrary and the results presented below hold as long as we focus on a symmetric Nash equilibrium.

Social welfare in market $m$ is defined by

$$
S W_{m}\left(q_{m}^{A}, q_{m}^{B}\right) \equiv U_{m}\left(q_{m}^{A}, q_{m}^{B}\right)-c \cdot\left(q_{m}^{A}+q_{m}^{B}\right)
$$

and thus the aggregate social welfare is given by

$$
S W\left(\left\{q_{m}^{A}, q_{m}^{B}\right\}_{m}\right) \equiv \sum_{m} S W_{m}\left(q_{m}^{A}, q_{m}^{B}\right)
$$

We measure social efficiency by this aggregate social welfare. We can also define aggregate consumer surplus by

$$
C S\left(\left\{p_{m}^{A}, p_{m}^{B}\right\}_{m}\right) \equiv \sum_{m} C S_{m}\left(p_{m}^{A}, p_{m}^{B}\right)
$$

where consumer surplus in market $m$ is

$$
C S_{m}\left(p_{m}^{A}, p_{m}^{B}\right) \equiv U_{m}\left[q_{m}^{A}\left(p_{m}^{A}, p_{m}^{B}\right), q_{m}^{B}\left(p_{m}^{A}, p_{m}^{B}\right)\right]-p_{m}^{A} q_{m}^{A}\left(p_{m}^{A}, p_{m}^{B}\right)-p_{m}^{B} q_{m}^{B}\left(p_{m}^{A}, p_{m}^{B}\right),
$$

and denote aggregate corporate surplus (profit) by

$$
\Pi\left(\left\{p_{m}^{A}, p_{m}^{B}\right\}_{m}\right) \equiv \sum_{m} \sum_{j}\left(p_{m}^{j}-c\right) q_{m}^{j}\left(p_{m}^{A}, p_{m}^{B}\right)
$$

so that the aggregate social welfare is divided in the following way:

$$
S W\left(\left\{q_{m}^{A}\left(p_{m}^{A}, p_{m}^{B}\right), q_{m}^{B}\left(p_{m}^{A}, p_{m}^{B}\right)\right\}_{m}\right)=C S\left(\left\{p_{m}^{A}, p_{m}^{B}\right\}_{m}\right)+\Pi\left(\left\{p_{m}^{A}, p_{m}^{B}\right\}_{m}\right) .
$$

\footnotetext{
${ }^{14}$ See Corts (1998) for interesting issues that arise from the asymmetric equilibrium.
} 
We consider two regimes, uniform pricing $(r=U)$ and price discrimination $(r=D)$ : under uniform pricing, firms set a common unit price for all separate markets. Under price discrimination, they can set a different price in each market. Throughout this paper, we restrict our attention to the case where all markets are served under both regimes.

Because the profit of firm $j \in\{A, B\}$ is given by

$$
\pi^{j}\left(p_{s}^{A}, p_{s}^{B}, p_{w}^{A}, p_{w}^{B}\right) \equiv \sum_{m}\left(p_{m}^{j}-c\right) q_{m}^{j}\left(p_{m}^{A}, p_{m}^{B}\right)
$$

we know that under symmetry, the symmetric equilibrium price under uniform pricing, $p^{*}$, is given by

$$
\left[q_{s}\left(p^{*}\right)+q_{w}\left(p^{*}\right)\right]+\left(p^{*}-c\right)\left[\frac{\partial q_{s}^{A}\left(p^{*}, p^{*}\right)}{\partial p_{m}^{A}}+\frac{\partial q_{w}^{A}\left(p^{*}, p^{*}\right)}{\partial p_{m}^{A}}\right]=0,
$$

while the equilibrium prices in market $m$ under price discrimination, $p_{m}^{*}$, are determined by the following first-order condition:

$$
q_{m}\left(p_{m}^{*}\right)+\left(p_{m}^{*}-c\right) \frac{\partial q_{m}^{A}\left(p_{m}^{*}, p_{m}^{*}\right)}{\partial p_{m}^{A}}=0
$$

Again, one caveat here is the well-known problem in the literature concerning thirddegree price discrimination: under uniform pricing, when a market is sufficiently small, it may not be served by either firm. While many papers in the literature simply assume that all markets are open under uniform pricing, we provide a more specific structure in the next subsection to guarantee this and to proceed further the analysis.

Note also the differences between Corts' (1998) study and this paper. Let $B R_{m}^{j}\left(p_{m}^{k}\right) \equiv$ $\arg \max _{p^{j}}\left(p^{j}-c\right) q_{m}^{j}\left(p^{j}, p_{m}^{-j}\right)$ be firm $j$ 's best response function in market $m$ under price discrimination, given firm $k$ 's price in market $m, p_{m}^{k}$. Corts (1998) makes four assumptions concerning the profit functions and the best response functions. In our settings, Assumptions 1-3 in Corts (1998) are all satisfied. ${ }^{15}$ However, Assumption 4 in Corts (1998), which in this paper is denoted by

$$
B R_{m}^{j}\left(p^{-j}\right)>B R_{-m}^{j}\left(p^{-j}\right)
$$

does not necessarily hold. In this sense, our model specification puts fewer restrictions on the economic fundamentals than Corts' (1998) study does.

\footnotetext{
${ }^{15}$ Assumption 1 in Corts (1998) ensures the uniqueness of the best response, Assumption 2 strategic complementarity, and Assumption 3 stability.
} 


\subsection{Solutions and Preliminary Results}

As an innocuous normalization, we set the constant marginal cost to zero, $c=0 .{ }^{16}$ Given that

$$
\frac{\partial q_{m}^{A}\left(p_{m}^{A}, p_{m}^{B}\right)}{\partial p_{m}^{A}}=-\frac{\beta_{m}}{\beta_{m}^{2}-\gamma_{m}^{2}}
$$

from (1) and that $q_{m}(p)=\left(\alpha_{m}-p\right) /\left(\beta_{m}+\gamma_{m}\right)$ is the symmetric demand function, the equilibrium discriminatory prices are (from (3))

$$
p_{m}^{*}=\frac{\alpha_{m}\left(\beta_{m}-\gamma_{m}\right)}{2 \beta_{m}-\gamma_{m}}
$$

and from (2) the equilibrium uniform price is

$$
p^{*}=\frac{\left(\beta_{w}-\gamma_{w}\right)\left(\beta_{s}-\gamma_{s}\right)\left[\left(\beta_{w}+\gamma_{w}\right) \alpha_{s}+\left(\beta_{s}+\gamma_{s}\right) \alpha_{w}\right]}{\left(2 \beta_{w}-\gamma_{w}\right)\left(\beta_{s}^{2}-\gamma_{s}^{2}\right)+\left(2 \beta_{s}-\gamma_{s}\right)\left(\beta_{w}^{2}-\gamma_{w}^{2}\right)}\left(\equiv p^{*}(\boldsymbol{\gamma}, \boldsymbol{\alpha}, \boldsymbol{\beta})\right)
$$

under the regime of uniform pricing (where $\boldsymbol{\gamma} \equiv\left(\gamma_{s}, \gamma_{w}\right), \boldsymbol{\alpha} \equiv\left(\alpha_{s}, \alpha_{w}\right)$ and $\boldsymbol{\beta} \equiv\left(\alpha_{s}, \alpha_{w}\right)$ ) if both markets are open. Appendix A2 shows that the weak market must be sufficiently large for neither firm to have an incentive to deviate to close it. It must also be small enough for the strong market to remain strong (i.e., the equilibrium prices under price discrimination are higher than under uniform pricing; see Footnote 10). Thus, we restrict the relative size in intercepts, $\alpha_{w} / \alpha_{s} \in\left(\underline{\alpha_{w} / \alpha_{s}}, \overline{\alpha_{w} / \alpha_{s}}\right)$. These upper and lower bounds are functions of $\boldsymbol{\gamma}$ and $\boldsymbol{\beta}$, and their precise expressions are given in Appendix A2. ${ }^{17}$

Notice that $\partial p_{m}^{*} / \partial \gamma_{m}=-\alpha_{m} \beta_{m} /\left(2 \beta_{m}-\gamma_{m}\right)^{2}<0$, which implies that as $\gamma_{m}$ becomes larger the discriminatory prices decreases. In addition, the uniform price and the discriminatory prices converge to the marginal cost because $\lim _{\gamma_{m} \uparrow \beta_{m}} p_{m}^{*}=0=\lim _{\gamma_{m} \uparrow \min \left(\beta_{m}\right)} p^{*}$ for all $m$. In contrast to the case of monopoly with linear demands, the difference in equilibrium aggregate output caused by regime change is not necessarily zero (see Appendix A1).

\footnotetext{
${ }^{16}$ Notice the innocuousness of the zero marginal cost assumption: it is equivalent to assuming a constant marginal cost if prices and consumers' willingness to pay are interpreted as the net cost (interpreting it as $\alpha_{m}-c$ as $\left.\alpha_{m}\right)$.

${ }^{17}$ The "weak" market is smaller than the "strong" market in the sense that the marginal utility $\partial U_{m}\left(q_{m}^{A}, q_{m}^{B}\right) / \partial q_{m}^{j}$ at $\left(q_{m}^{A}, q_{m}^{B}\right)=(0,0)$ is greater in the strong market.
} 


\section{$3 \quad$ Welfare Analysis}

This section consists of two subsections. The first subsection presents analytical properties that are useful for welfare analysis. We then investigate the welfare effects of price discrimination in the second subsection.

\subsection{Analytical Properties}

In symmetric equilibrium, social welfare under regime $r \in\{D, U\}$ is written as

$$
S W^{r}=2\left(\alpha_{s} q_{s}^{r}+\alpha_{w} q_{w}^{r}\right)-\left(\beta_{s}+\gamma_{s}\right)\left[q_{s}^{r}\right]^{2}-\left(\beta_{w}+\gamma_{w}\right)\left[q_{w}^{r}\right]^{2}
$$

where $q_{m}^{D}=q_{m}\left(p_{m}^{*}\right)$ and $q_{m}^{U}=q_{m}\left(p^{*}\right)$ are the equilibrium quantities in market $m$ under the regimes of price discrimination and of uniform pricing, respectively (see Appendix A1 for the actual functional forms). Let $\Delta S W^{*}$ be defined by the equilibrium difference $S W^{D}-S W^{U}$. It is then given by

$$
\begin{aligned}
\Delta S W^{*}= & \Delta S W^{*}(\boldsymbol{\gamma}, \boldsymbol{\alpha}, \boldsymbol{\beta}) \\
\equiv & 2\left[\alpha_{s}\left(q_{s}^{D}-q_{s}^{U}\right)+\alpha_{w}\left(q_{w}^{D}-q_{w}^{U}\right)\right] \\
& -\left(\beta_{s}+\gamma_{s}\right)\left(q_{s}^{D}-q_{s}^{U}\right)\left(q_{s}^{D}+q_{s}^{U}\right)-\left(\beta_{w}+\gamma_{w}\right)\left(q_{w}^{D}-q_{w}^{U}\right)\left(q_{w}^{D}+q_{w}^{U}\right) \\
= & \Delta q_{s}^{*}\left[2 \alpha_{s}-\left(\beta_{s}+\gamma_{s}\right)\left(q_{s}^{D}+q_{s}^{U}\right)\right]+\Delta q_{w}^{*}\left[2 \alpha_{w}-\left(\beta_{w}+\gamma_{w}\right)\left(q_{w}^{D}+q_{w}^{U}\right)\right],
\end{aligned}
$$

where $\Delta q_{m}^{*} \equiv q_{m}^{D}-q_{m}^{U}$. It is further shortened, and thus we have the following proposition (see the proof in Appendix A3):

Proposition 1. The equilibrium difference $\Delta S W^{*}=\Delta S W^{*}(\boldsymbol{\gamma}, \boldsymbol{\alpha}, \boldsymbol{\beta})$ is given by

$$
\Delta S W^{*}(\boldsymbol{\gamma}, \boldsymbol{\alpha}, \boldsymbol{\beta})=-\sum_{m \in\{s, w\}} \frac{\Delta p_{m}^{*}}{\beta_{m}+\gamma_{m}} \cdot\left(p_{m}^{*}+p^{*}\right),
$$

where $\Delta p_{m}^{*} \equiv p_{m}^{*}-p^{*}$.

This expression has the following graphical interpretation. Figure 1 shows the relationship between $\Delta p_{m}^{*}$ and $\Delta q_{m}^{*}$. As Appendix A1 demonstrates, we have $\Delta p_{m}^{*}=$ $-\left(\beta_{m}+\gamma_{m}\right) \Delta q_{m}^{*}$. This relationship can be interpreted as the situation where in symmetric equilibrium any firm faces the "virtual" inverse demand function, $p_{m}=\alpha_{m}-\left(\beta_{m}+\right.$ 


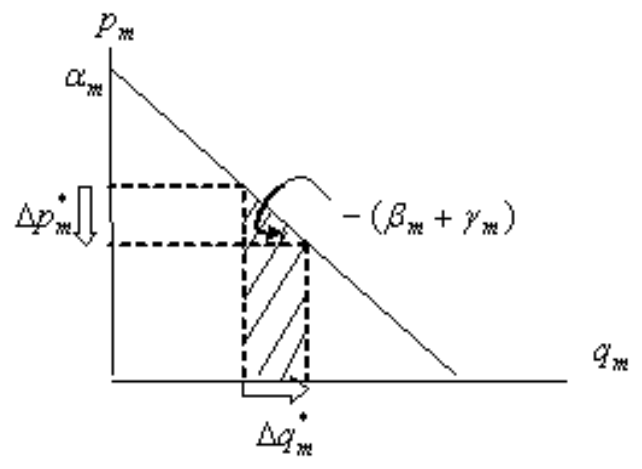

Figure 1: Equilibrium Changes in Quantity and Price in Market $m$ (for any firm)

$\left.\gamma_{m}\right) q_{m}$, in market $m$ (notice the difference from the original inverse demand function, $\left.p_{m}^{j}\left(q_{m}^{j}, q_{m}^{-j}\right)=\alpha_{m}-\beta_{m} q_{m}^{j}-\gamma_{m} q_{m}^{-j}\right)$. The welfare change in market $m$ is depicted by the shaded trapezoid in Figure 1 (in this example, it is a welfare gain). Thus, its size is calculated by the sum of the upper and bottom segments $\left(p_{m}^{*}+p^{*}\right)$ multiplied by height $\left(\Delta q_{m}^{*}=-\Delta p_{m}^{*} /\left(\beta_{m}+\gamma_{m}\right)\right)$, divided by two. Noting that two identical firms exist in market $m$, we have $-\Delta p_{m}^{*}\left(p_{m}^{*}+p^{*}\right) /\left(\beta_{m}+\gamma_{m}\right)$ as a welfare change in market $m$.

If it is positive (when $\Delta p_{m}^{*}<0$ ), then it is a welfare gain. Similarly, if it is negative (when $\Delta p_{m}^{*}>0$ ), then it is a welfare loss. Other things being equal, the greater the value of $\gamma_{m}$, the gentler (and hence more elastic) the equilibrium inverse demand curve becomes. Complementarity between the brands makes the equilibrium inverse demand curve steep, and substitutability makes it gentle.

We have the following property of the price elasticity. A simple calculation leads to the following lemma:

Lemma 1. Let the price elasticity of demand in market $m$ in equilibrium be defined by

$$
\varepsilon_{m}\left(p_{m}^{*}\right) \equiv\left|-\frac{d q_{m}\left(p_{m}^{*}\right)}{d p_{m}^{*}} \frac{p_{m}^{*}}{q_{m}^{D}}\right|,
$$

where $q_{m}\left(p_{m}^{*}\right)=\left(\alpha_{m}-p_{m}^{*}\right) /\left(\beta_{m}+\gamma_{m}\right)$. Then, the equilibrium price elasticity of demand is expressed by

$$
\varepsilon_{m}\left(p_{m}^{*}\right)=\underbrace{1}_{\text {market elasticity }}+\underbrace{\left(-\frac{\gamma_{m}}{\beta_{m}}\right)}_{\text {cross-price elasticity }}
$$


Notice that $\varepsilon_{m}\left(p_{m}^{*}\right)$ is a constant, and does not depend on either $q_{m}^{D}$ or even the intercept, $\alpha_{m}$. This decomposition is a special result of Holmes' (1989, p.246) general result: firm-level elasticity is the sum of the market elasticity and the cross-price elasticity. ${ }^{18}$

The market elasticity of demand is a unit-free measure of responsiveness of the firms as a whole. However, strategic interaction distinguishes it from the elasticity on which each firm bases its decision making: the cross-price elasticity measures of how much each firm "damages" the other firm in equilibrium. In our model, strategic interaction is created by the very fact that firms (horizontally) differentiate their products or services. Notice that the market elasticity is exactly one as in the case of a one-good monopoly with a linear demand curve (remember that price elasticity of demand is one when the marginal revenue curve crosses the constant marginal cost curve (i.e., the horizontal axis)).

As we mention in Section 2 , the ratio $\gamma_{m} / \beta_{m} \in(-1,1)$ is interpreted as the normalized measure of horizontal product differentiation in market $m$. The cross-price elasticity in Holmes (1989) is simply expressed by the negative of the ratio alone. From (4), we have the relationship, $\varepsilon_{m}\left(p_{m}^{*}\right) \lesseqgtr 1$ if and only if $\gamma_{m} \gtreqless 0$. That is, if the brands are complements $\left(\gamma_{m}<0\right)$, then the firm-level elasticity in equilibrium is greater than one, meaning that a one percent price cut by one firm creates more than a one percent increase in its demand, and thus an increase in revenue (hence in profit). On the other hand, a less than one percent increase in demand follows if the brands are substitutes $\left(\gamma_{m}>0\right)$. These facts imply that complementarity (resp. substitutability) in market $m$ keeps the equilibrium prices relatively high (resp. low).

As to changes in equilibrium aggregate output, $\Delta Q^{*}$ (see Appendix A1 for the derivation), it is shown that if the aggregate output is not increased by price discrimination, then social welfare deteriorates, as verified by Bertoletti (2004) in the case of monopolies with linear and nonlinear demands (see Appendix A4 for the proof). ${ }^{19}$

Proposition 2. Social welfare must be decreased by price discrimination if a change in aggregate output is not positive (i.e., $\Delta Q^{*} \leq 0 \Rightarrow \Delta S W^{*}<0$ ).

\footnotetext{
${ }^{18}$ Holmes (1989) shows the decomposition under the assumption of symmetric demands between firms: it also holds off equilibrium. The term "market elasticity" is borrowed from Stole (2007) (Holmes (1989) originally called it the "industry-demand elasticity").

${ }^{19}$ Bertoletti's (2004) result is a generalization of the well-known result of Varian (1985) and Schwartz (1990) who state that $\Delta Q^{*}<0 \Rightarrow \Delta S W^{*}<0$.
} 
Given that market $s$ is strong $\left(\alpha_{s} / \alpha_{w}>\alpha_{s} / \alpha_{w}\right)$, we have the following relationship:

$$
\Delta Q^{*} \gtreqless 0 \Leftrightarrow \frac{\gamma_{s}}{\beta_{s}} \gtreqless \frac{\gamma_{w}}{\beta_{w}},
$$

which is a special case of Holmes' (1989) result that includes nonlinear demands. Holmes (1989, p.247) shows that a change in the aggregate output resulting from price discrimination is positive if and only if the sum of the two terms, the "adjusted-concavity condition" and "elasticity-ratio condition", is positive. As its name implies, the first term is related to the demand curvature, and in our case of linear demands, it is zero. The second term is written as

$$
\frac{\text { cross-price elasticity in market } s}{\text { market elasticity in market } s}-\frac{\text { cross-price elasticity in market } w}{\text { market elasticity in market } w},
$$

which is equivalent to $\gamma_{s} / \beta_{s}-\gamma_{w} / \beta_{w}$ from Lemma 1 . The result that the output change, $\Delta Q^{*}$, can be positive in oligopoly is in sharp contrast with the case in monopoly where the output change is always zero with linear demand. In the next subsection, we explore the possibility of $\Delta S W^{*}>0$ in the differentiated oligopoly.

However, a positive change in social welfare is solely due to an improvement in the firms' profits. This is because a change in aggregate consumer surplus is always negative. Let $\Delta C S^{*}$ be defined by the equilibrium difference between aggregate consumer surpluses under price discrimination and under uniform pricing $\left(C S^{D}-C S^{U}\right)$. We then have the following result (see Appendix A5 for the proof).

Proposition 3. Price discrimination always deteriorates aggregate consumer surplus (i.e., $\Delta C S^{*}<0$ for all exogenous parameters).

\subsection{Welfare-Improving Price Discrimination}

We now explore the possibility of $\Delta S W^{*}(\boldsymbol{\gamma}, \boldsymbol{\alpha}, \boldsymbol{\beta})>0$. After some calculus, we have the following statement:

Proposition 4. $\Delta S W^{*}(\boldsymbol{\gamma}, \boldsymbol{\alpha}, \boldsymbol{\beta})>0$ if and only if

$$
\frac{\alpha_{w}}{\alpha_{s}}>\frac{L_{w}}{L_{s}}
$$

where $L_{i} \equiv\left(2 \beta_{i}-\gamma_{i}\right)\left(\beta_{j}-\gamma_{j}\right)\left(\left(2 \beta_{i}-\gamma_{i}\right)^{2}\left(\beta_{j}-\gamma_{j}\right)^{2}\left(\beta_{j}+\gamma_{j}\right)+\left(\beta_{i}^{2}-\gamma_{i}^{2}\right)\left(2 \beta_{j}-\gamma_{j}\right)\left(2 \beta_{i}\left(\beta_{j}-\right.\right.\right.$ $\left.\left.\left.\gamma_{j}\right)-\left(\beta_{i}-\gamma_{i}\right) \gamma_{j}\right)\right), i=w, s, j \neq i$. 
To further interpret this equation and explore the possibility that $\Delta S W^{*}(\boldsymbol{\gamma}, \boldsymbol{\alpha}, \boldsymbol{\beta})>0$, we now reduce the number of the parameters. More specifically, we assume that $\alpha_{s}=1>$ $\alpha_{w}>0$. This is because price discrimination never improves welfare if $\alpha_{s}=\alpha_{w}$ (the formal proof is available upon request). Thus, $\alpha_{s} / \alpha_{w}>1$ is necessary for social welfare to improve.

In the following analysis, we first consider the case of symmetry in product differentiation in the strong and weak markets $\left(\gamma_{s} / \beta_{s}=\gamma_{w} / \beta_{w}\right)$. We then allow asymmetric product differentiation. To do so, we first construct an intuitive argument why price discrimination improves social welfare. Given the equilibrium discriminatory price is higher (lower) than the uniform price in the strong (weak) market, we know that (note that, $\left.\Delta q_{m}^{*}=-\Delta p_{m}^{*} /\left(\beta_{m}+\gamma_{m}\right)\right)$

$$
\Delta S W^{*}>0 \Leftrightarrow \Delta q_{w}^{*} \cdot\left(p^{*}+p_{w}^{*}\right)>\Delta q_{s}^{*} \cdot\left(p^{*}+p_{s}^{*}\right) .
$$

For the latter inequality to hold, (1) $\Delta q_{w}^{*}$ or $\left(p^{*}+p_{w}^{*}\right)$ is sufficiently large, and/or (2) $\left|\Delta q_{s}^{*}\right|$ or $\left(p^{*}+p_{s}^{*}\right)$ is sufficiently small. Figure 2 shows the asymmetry between the strong and the weak markets. Notice that the upper segment of the trapezoid of the welfare loss in the strong market and the bottom segment of the trapezoid of the welfare gain in the weak market have the same length $\left(p^{*}\right)$. Thus, the larger $\left|\Delta q_{s}^{*}\right|$, the larger $\left(p^{*}+p_{s}^{*}\right)$ is. On the other hand, the larger $\Delta q_{w}^{*}$, the smaller $\left(p^{*}+p_{w}^{*}\right)$ is. Hence, the smaller $\left|\Delta q_{s}^{*}\right|$, the better it is for welfare improvement, while $\Delta q_{w}^{*}$ should not be too small or too large.

\subsubsection{The Case of Symmetric Product Differentiation}

Let the situation be called symmetric product differentiation if the measures of horizontal product differentiation coincide in the two markets (i.e., $\gamma_{s} / \beta_{s}=\gamma_{w} / \beta_{w}$ ). In this case, the two markets are homothetic in the sense that the only difference in the two markets is in the intercepts of the inverse demand curves. It is shown that if $\gamma_{s}=\gamma_{w}$ and $\beta_{s}=\beta_{w}$, then $\Delta Q^{*}=0$ (see Appendix A1). This means that $\left|\Delta q_{w}^{*}\right|=\left|\Delta q_{s}^{*}\right|$. Because $p_{s}^{*}$ is greater than $p_{w}^{*}$ (which comes from the assumption $\alpha_{s}>\alpha_{w}$ ), the loss in the strong market is always larger than the gain in the weak market. We thus have the following proposition: Proposition 5. In the case of symmetric product differentiation, social welfare is never improved by price discrimination (i.e., $\Delta S W^{*}<0$ for all exogenous parameters). 


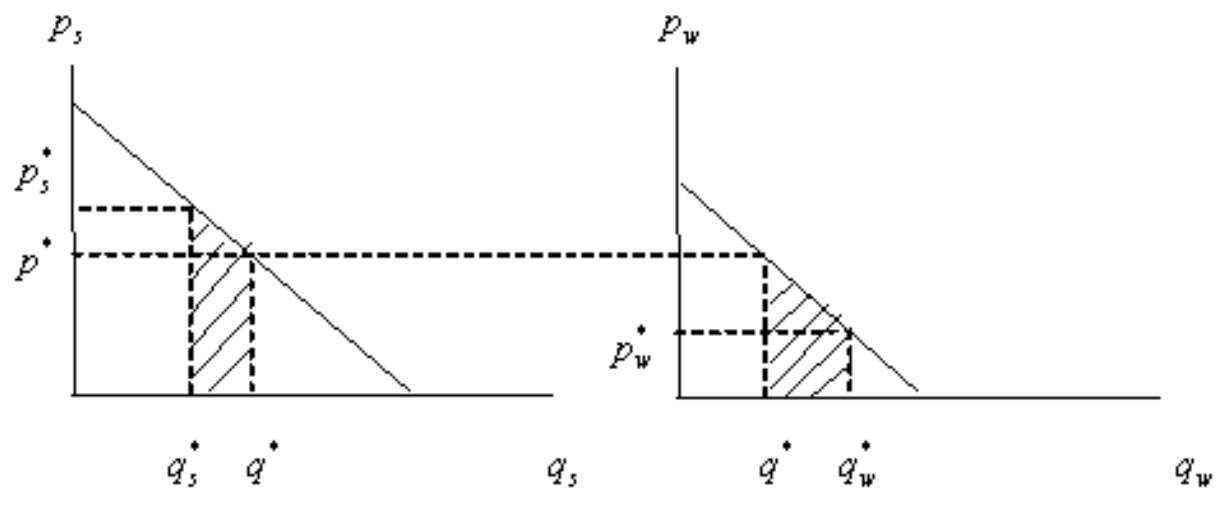

Figure 2: Asymmetry between the Strong and the Weak Markets

We therefore need to consider the case of $\gamma_{s} \beta_{w} \neq \gamma_{w} \beta_{s}$, which is called asymmetric product differentiation, to study the possibility that $\Delta S W^{*}>0$.

\subsubsection{The Case of Asymmetric Product Differentiation}

To simplify the analysis, we assume that $\beta_{s}=\beta_{w}$. By so doing, we are able to focus on the effects of $\left(\gamma_{s}, \gamma_{w}\right)$ on social welfare. More specifically, we allow $\gamma_{s}$ and $\gamma_{w}$ to differ, letting $\beta \equiv \beta_{s}=\beta_{w}$ to avoid unnecessary complications (Appendix A6 gives an analysis with $\gamma_{s}=\gamma_{w}$ to show the effects of $\beta_{s}=\beta_{w}$ on social welfare). We present numerical and graphical arguments on the domains $\left(\gamma_{s}, \gamma_{w}\right)$ that make $\Delta S W^{*}>0$ for fixed values of $\left(\alpha_{w}, \beta_{s}, \beta_{w}\right)$.

Figure 3 depicts the region of $\Delta S W^{*}>0$ with $\alpha_{w}=0.85$ and $\beta=1.0$ (the shaded area). ${ }^{20}$ Consider first the case of substitutable goods $\left(\gamma_{s}>0\right.$ and $\left.\gamma_{w}>0\right)$. Remember from Proposition 2 that for the total social surplus to be improved by price discrimination it is necessary that $\Delta Q^{*}>0 \Leftrightarrow \gamma_{s} / \beta_{s}>\gamma_{w} / \beta_{w}$, that is, $\gamma_{s}>\gamma_{w}$ in this specification. Substitutability in the strong market must be larger than that in the weak market for a welfare improvement. Remember that the slope of the equilibrium demand in the strong market $-\left(\beta_{s}+\gamma_{s}\right)$ is steeper than that in the weak market. This is associated with a

\footnotetext{
${ }^{20}$ It is verified that all of the model parameters in the analysis below satisfy the restriction conditions provided in Appendix A2.
} 


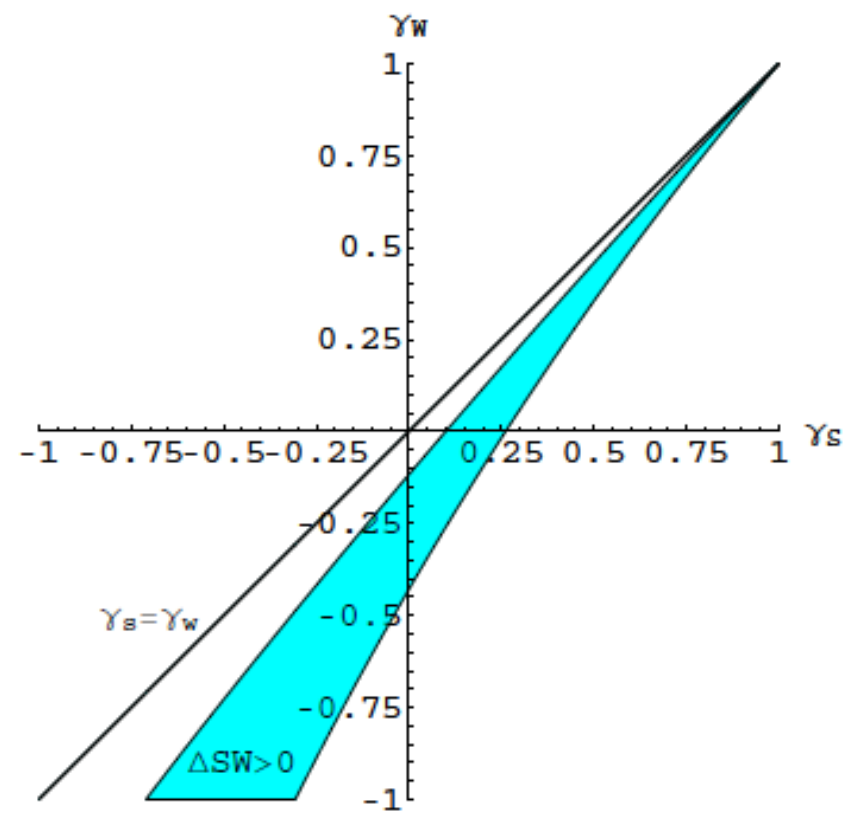

Figure 3: The Region of $\Delta S W^{*}>0$ for the Case of $\alpha_{w}=0.85$ and $\beta_{s}=\beta_{w}=1.0$

larger increase in output in the weak market rather than a decrease in output in the strong market. Why is there a bottom right boundary of the region for $\Delta S W^{*}>0$ ? It derives from the restriction that market $s$ and $w$ are strong and weak markets respectively: $\alpha_{w} / \alpha_{s}<\overline{\alpha_{w} / \alpha_{s}}(\boldsymbol{\gamma}, \boldsymbol{\beta})$ (the details are available upon request). In the unshaded southeastern area, this inequality does not hold. That is, $p_{s}^{*}<p^{*}<p_{w}^{*}$ in equilibrium. In other words, market $s$ and $w$ are actually "weak" and "strong" markets, respectively. In this area, the substitutability in the actual strong market (market $w$ ) is lower than that in the actual weak market (market $s$ ), i.e., $\gamma_{w}<\gamma_{s}$. As mentioned earlier, $\Delta S W^{*}>0$ only if the actual strong market is more elastic. Therefore, $\Delta S W^{*}<0$ in the unshaded southeastern area.

Notice that price discrimination never improves social welfare in the second quadrant $\left(\gamma_{s}<0<\gamma_{w}\right)$. That is, if the two brands are complementary in the strong market $\left(\gamma_{s}<0\right)$ while the firms sell substitutable goods in the weak market $\left(\gamma_{w}>0\right)$, then price discrimination necessarily deteriorates social welfare. This result seems to hold for other parameter values because $\Delta S W^{*} \leq 0$ if $\beta_{s}=\beta_{w}$ and $\gamma_{s}=\gamma_{w}$ : in the northwestern region separated by $\gamma_{s}=\gamma_{w}$, social welfare would be negative. The intuitive reason is that 
complementarity in the strong market makes the price change caused by discrimination more responsive, which creates more inefficiency, while substitutability in the weak market makes the price change less responsive. The latter positive effect is not sufficiently large to outweigh the former negative effect.

On the other hand, it is possible that price discrimination improves social welfare if the firms' brands are substitutes in the strong market $\left(\gamma_{s}>0\right)$ and are complements in the weak market $\left(\gamma_{w}<0\right)$. Figure 3 also shows that the combination of a high degree of complementarity in the weak market and a low degree of complementarity in the weak market (i.e., $\left|\gamma_{w}\right|$ larger than $\left|\gamma_{s}\right|$ ) is suited to welfare gain. This result is as expected: strong complementarity in the weak market keeps the discriminatory price low enough to offset the loss from the price increase in the strong market. However, it has been verified that consumer surplus is never improved by price discrimination (Proposition 3).

Analytical arguments for these results are provided as follows. Fix $\gamma_{w} \in(-1,1)$, and notice that $\Delta S W^{*}=0$ if $\left(\gamma_{s}, \gamma_{w}\right)$ satisfies $\overline{\alpha_{w} / \alpha_{s}}(\boldsymbol{\gamma}, \boldsymbol{\beta})=\alpha_{w} / \alpha_{s}$. This equality is rewritten as

$$
\begin{aligned}
\frac{\alpha_{w}}{\alpha_{s}} & =\frac{\left(\beta_{s}-\gamma_{s}\right)\left(2 \beta_{w}-\gamma_{w}\right)}{\left(\beta_{w}-\gamma_{w}\right)\left(2 \beta_{s}-\gamma_{s}\right)} \\
& \Leftrightarrow \gamma_{s}=\frac{\beta_{s}\left[2\left(\alpha_{s}-\alpha_{w}\right) \beta_{w}-\left(\alpha_{s}-2 \alpha_{w}\right) \gamma_{w}\right]}{\left(2 \alpha_{s}-\alpha_{w}\right) \beta_{w}-\left(\alpha_{s}-\alpha_{w}\right) \gamma_{w}} \equiv \bar{\gamma}_{s} .
\end{aligned}
$$

Substituting $\bar{\gamma}_{s}$ into $\partial \Delta S W^{*} / \partial \gamma_{s}$, we have the following result:

$$
\left.\frac{\partial \Delta S W^{*}}{\partial \gamma_{s}}\right|_{\gamma_{s}=\bar{\gamma}_{s}}<0
$$

Thus, we have the following proposition:

Proposition 6. There exists $\gamma_{s}^{\prime}$ such that $\Delta S W^{*}>0$ for $\gamma_{s} \in\left(\gamma_{s}^{\prime}, \bar{\gamma}_{s}\right)$.

In other words, given the values of $\gamma_{w}$ and $\gamma_{s}$ that satisfy $\overline{\alpha_{w} / \alpha_{s}}(\boldsymbol{\gamma}, \boldsymbol{\beta})=\alpha_{w} / \alpha_{s}$, a slight decrease in $\gamma_{s}$ enhances $\Delta S W^{*}$. This is consistent with the result in Figure 3.

Lastly, we focus on one case of asymmetric product differentiation. Table 1 shows the result for the case of $\alpha_{w}=0.85$ and $\beta_{s}=\beta_{w}=1.0$. The first case, where the two brands are substitutes in the strong market while they are complementary goods in the weak market, has smaller changes in both prices and output than the second case has. Social 


\begin{tabular}{c|cc}
\hline \hline & $\left(\gamma_{s}, \gamma_{w}\right)=$ & \\
& $(0.1,-0.1)$ & $(-0.1,0.1)$ \\
\hline$p^{*}$ & 0.4588 & 0.4663 \\
$p_{s}^{*}\left(\Delta p_{s}^{*} / p^{*}\right)$ & $0.4737(3 \%)$ & $0.5238(12 \%)$ \\
$p_{w}^{*}\left(\Delta p_{w}^{*} / p^{*}\right)$ & $0.4452(-3 \%)$ & $0.4026(-14 \%)$ \\
$\Delta q_{s}^{*}\left(\Delta q_{s}^{*} / q_{s}^{*}\left(p^{*}\right)\right)$ & $-0.0615(-3 \%)$ & $-0.0640(-11 \%)$ \\
$\Delta q_{w}^{*}\left(\Delta q_{w}^{*} / q_{w}^{*}\left(p^{*}\right)\right)$ & $0.0150(3 \%)$ & $0.0578(17 \%)$ \\
\hline$\Delta S W^{*}$ & 0.0009 & -0.0131 \\
$\Delta C S_{s}^{*}$ & -0.0145 & -0.0646 \\
$\Delta C S_{w}^{*}$ & 0.0120 & 0.0481 \\
$\Delta \Pi^{*}$ & 0.0034 & 0.0034 \\
\hline$\Delta Q^{*}$ & 0.0014 & -0.0061 \\
\hline \hline
\end{tabular}

Table 1: Asymmetric Product Differentiation $\left(\alpha_{w}=0.85\right.$ and $\left.\beta=1.0\right)$

welfare is improved by price discrimination in the first case. The price differentials in the latter case are greater: what happens after the regime change from uniform pricing to price discrimination is that while competition in the weak market becomes fiercer due to substitutability, complementarity softens the competition to increase discriminatory price in the strong market.

\section{Concluding Remarks}

In this paper, we study the relationship between horizontal product differentiation and the welfare effects of third-degree price discrimination in oligopoly with linear demands. By deriving linear demands from a representative consumer's utility and focusing on symmetric equilibrium in a pricing game, we characterize conditions relating to such demand properties as substitutability and complementarity for price discrimination to improve social welfare. In particular, we show that price discrimination can improve social welfare (especially) if firms' brands are substitutes in the market where the discriminatory price is higher and are complements in the market where it is lower, but it never improves in the reverse case. We verify, however, that consumer surplus is never improved by price discrimination: welfare improvement by price discrimination is solely the result of an increase in the firms' profits. Accordingly, this means that there is no chance that firms will suffer from "prisoners' dilemma", that is, firms are better off switching from uniform 
pricing to price discrimination.

In the present paper, we focus only on symmetric equilibrium of the pricing game to gain analytical insight. In particular, the equilibrium amount of output is common for all firms under either uniform pricing or price discrimination. This limitation would be particularly unappealing if one wished to compare the equilibrium predictions from our model with empirical data. ${ }^{21}$ This and other interesting issues await future research.

\section{Appendices}

\section{A1. Changes in Equilibrium Prices and Quantities by Price Discrimina- tion}

Equilibrium quantities produced by each firm under price discrimination in market $m$ are

$$
q_{m}\left(p_{m}^{*}\right)=\frac{\alpha_{m} \beta_{m}}{\left(2 \beta_{m}-\gamma_{m}\right)\left(\beta_{m}+\gamma_{m}\right)},
$$

where the denominator is positive because $\left|\gamma_{m}\right|<\beta_{m}$.

Under uniform pricing, if both markets are open (see Appendix A2 for the verification of market opening), then tedious calculation shows that the equilibrium uniform price is

$$
p^{*}=\frac{\left(\beta_{m}-\gamma_{m}\right)\left(\beta_{m^{\prime}}-\gamma_{m^{\prime}}\right)\left[\alpha_{m}\left(\beta_{m^{\prime}}+\gamma_{m^{\prime}}\right)+\alpha_{m^{\prime}}\left(\beta_{m}+\gamma_{m}\right)\right]}{\Phi^{U}},
$$

where $m \neq m^{\prime}\left(m, m^{\prime} \in\{s, w\}\right)$ and $\Phi^{U} \equiv \sum_{m \neq m^{\prime}}\left(\beta_{m}^{2}-\gamma_{m}^{2}\right)\left(2 \beta_{m^{\prime}}-\gamma_{m^{\prime}}\right)$. The denominator and the numerator are also found to be positive because $\left|\gamma_{m}\right|<\beta_{m}$. One can verify that the equilibrium quantities under uniform pricing in market $m \neq m^{\prime}$ are then given by

$$
q_{m}\left(p^{*}\right)=\frac{\alpha_{m}\left[\beta_{m}\left(\beta_{m^{\prime}}^{2}-\gamma_{m^{\prime}}^{2}\right)+\beta_{m^{\prime}}\left(\beta_{m}^{2}-\gamma_{m}^{2}\right)\right]+\left(\alpha_{m}-\alpha_{m^{\prime}}\right)\left(\beta_{m}^{2}-\gamma_{m}^{2}\right)\left(\beta_{m^{\prime}}-\gamma_{m^{\prime}}\right)}{\left(\beta_{m}+\gamma_{m}\right) \Phi^{U}} .
$$

Now, let

$\Delta p_{m}^{*} \equiv p_{m}^{*}-p^{*}=\frac{\left(\beta_{m}^{2}-\gamma_{m}^{2}\right)\left[\alpha_{m}\left(\beta_{m}-\gamma_{m}\right)\left(2 \beta_{m^{\prime}}-\gamma_{m^{\prime}}\right)-\alpha_{m^{\prime}}\left(\beta_{m^{\prime}}-\gamma_{m^{\prime}}\right)\left(2 \beta_{m}-\gamma_{m}\right)\right]}{\left(2 \beta_{m}-\gamma_{m}\right) \Phi^{U}}$

\footnotetext{
${ }^{21}$ Galera and Zaratieguia (2006) consider duopolistic third-degree price discrimination with heterogeneity in constant marginal cost and show that price discrimination can improve social welfare even if the total output does not change. This favors the low-cost firm to cut its prices significantly, and this cost saving may overcome the welfare losses from price discrimination.
} 
be defined as the changes in the equilibrium prices resulting from a move uniform pricing to price discrimination in each market. Thus, if we define the strong (weak) market as that where the equilibrium price increases (decreases) by price discrimination, then market $m$ is strong if and only if

$$
\alpha_{m}>\frac{\left(\beta_{m^{\prime}}-\gamma_{m^{\prime}}\right)\left(2 \beta_{m}-\gamma_{m}\right)}{\left(\beta_{m}-\gamma_{m}\right)\left(2 \beta_{m^{\prime}}-\gamma_{m^{\prime}}\right)} \alpha_{m^{\prime}} .
$$

This implies that, in contrast to the case of monopoly with inter-market dependencies (see Adachi (2002)), the condition on the intercepts, $\alpha_{m}>\alpha_{m^{\prime}}$, is not exactly the necessary and sufficient condition for market $m$ to be strong: if $\gamma_{m^{\prime}} \beta_{m}$ is much larger than $\gamma_{m} \beta_{m^{\prime}}$ (note that either or both can be negative), then market $m$ with $\alpha_{m}>\alpha_{m^{\prime}}$ can be weak. Of course, if $\beta_{m}=\beta_{m^{\prime}}$ and $\gamma_{m}=\gamma_{m^{\prime}}$, then $\alpha_{m}>\alpha_{m^{\prime}}$ is the necessary and sufficient condition for market $m$ to be strong.

Turning our attention to output, we have

$$
\begin{aligned}
\Delta q_{m}^{*} & \equiv q_{m}\left(p_{m}^{*}\right)-q_{m}\left(p^{*}\right) \\
& =-\frac{\left(\beta_{m}-\gamma_{m}\right)\left[\alpha_{m}\left(\beta_{m}-\gamma_{m}\right)\left(2 \beta_{m^{\prime}}-\gamma_{m^{\prime}}\right)-\alpha_{m^{\prime}}\left(\beta_{m^{\prime}}-\gamma_{m^{\prime}}\right)\left(2 \beta_{m}-\gamma_{m}\right)\right]}{\left(2 \beta_{m}-\gamma_{m}\right) \Phi^{U}}
\end{aligned}
$$

as the equilibrium changes in output resulting from a more from uniform pricing to price discrimination for each firm in strong and weak markets, respectively. It is then verified that $\Delta p_{m}^{*}$ and $\Delta q_{m}^{*}$ are related in the following way:

$$
\Delta p_{m}^{*}=-\left(\beta_{m}+\gamma_{m}\right) \Delta q_{m}^{*}
$$

so that we have $q_{m}\left(p_{m}^{*}\right)>q_{m}\left(p^{*}\right)$ if and only if $p_{m}^{*}<p^{*}$. One can also derive the change in equilibrium aggregate output:

$$
\Delta Q^{*} \equiv \Delta q_{s}^{*}+\Delta q_{w}^{*}=\frac{\left(\beta_{w} \gamma_{s}-\beta_{s} \gamma_{w}\right)\left[\alpha_{s}\left(\beta_{s}-\gamma_{s}\right)\left(2 \beta_{w}-\gamma_{w}\right)-\alpha_{w}\left(\beta_{w}-\gamma_{w}\right)\left(2 \beta_{s}-\gamma_{s}\right)\right]}{\left(2 \beta_{s}-\gamma_{s}\right)\left(2 \beta_{w}-\gamma_{w}\right) \Phi^{U}}
$$

which does not necessarily coincides with zero, as opposed to the case of monopoly with linear demands.

Now, although market $m$ is strong even if $\alpha_{m}=\alpha_{m^{\prime}}$ as long as $\left(\beta_{m}-\gamma_{m}\right)\left(2 \beta_{m^{\prime}}-\right.$ $\left.\gamma_{m^{\prime}}\right)>\left(\beta_{m^{\prime}}-\gamma_{m^{\prime}}\right)\left(2 \beta_{m}-\gamma_{m}\right)$, we assume that $\alpha_{m} \neq \alpha_{m^{\prime}}$. This is because if $\alpha_{m}=\alpha_{m^{\prime}}$, then we have

$$
\Delta Q^{*}=-\frac{\alpha_{m}\left(\beta_{m^{\prime}} \gamma_{m}-\beta_{m} \gamma_{m^{\prime}}\right)^{2}}{\left(2 \beta_{m}-\gamma_{m}\right)\left(2 \beta_{m^{\prime}}-\gamma_{m^{\prime}}\right) \Phi^{U}} \leq 0
$$




$$
\Delta p_{m}^{*}=\frac{\alpha_{m}\left(\beta_{m}^{2}-\gamma_{m}^{2}\right)\left(\beta_{m} \gamma_{m^{\prime}}-\beta_{m^{\prime}} \gamma_{m}\right)}{\left(2 \beta_{m}-\gamma_{m}\right) \Phi^{U}}
$$

and most importantly, $\Delta S W^{*}$, the difference in social welfare under price discrimination and under uniform pricing (introduced in Section 3), can never be positive (the formal proof is upon request). Thus, unequal values of intercepts of the two markets are necessary for price discrimination to improve social welfare. Hence, for markets $s$ and $w$ to be strong and weak, respectively, it is necessary for the weak market to be sufficiently small:

$$
\frac{\alpha_{w}}{\alpha_{s}}<\min \left[\frac{\left(\beta_{s}-\gamma_{s}\right)\left(2 \beta_{w}-\gamma_{w}\right)}{\left(\beta_{s}-\gamma_{s}\right)\left(2 \beta_{w}-\gamma_{w}\right)}, 1\right] .
$$

The reason why this is not a sufficient condition is that we must verify the parameter restrictions for market $w$ to be sufficiently large to be open under uniform pricing. We verify them in Appendix A2.

For later use (Appendix A3), we also calculate the sum of a firm's output under uniform pricing and the under price discrimination in each market $m \in\{s, w\}$ :

$$
q_{m}\left(p_{m}^{*}\right)+q_{m}\left(p^{*}\right)=\frac{\alpha_{m}\left(3 \beta_{m}-\gamma_{m}\right)}{\left(\beta_{m}+\gamma_{m}\right)\left(2 \beta_{m}-\gamma_{m}\right)}-\frac{p^{*}}{\beta_{m}+\gamma_{m}} .
$$

\section{A2. Market Opening under Uniform Pricing}

Remember that the symmetric equilibrium under uniform pricing in the main text and Appendix A1 is obtained, given that both markets are supplied by either firm under uniform pricing $\left(q_{s}\left(p^{*}\right)>0\right.$ and $\left.q_{w}\left(p^{*}\right)>0\right)$. In this appendix, we obtain a (sufficient) condition guaranteeing that in equilibrium each firm supplies to the weak market under uniform pricing. To do so, we consider one firm's incentive not to deviate from the equilibrium by stopping its supply to the weak market.

Suppose firm $j$ supplies only to the strong market, given that the rival firm supplies both markets with the equilibrium price, $p^{*}$ (see Appendix A1). Let firm $j$ 's price when deviating from the equilibrium price under the uniform pricing regime be denoted by $p^{\prime}$. Then, when firm $j$ closes the weak market, its profit is written by ${ }^{22}$

$$
\widetilde{\pi}\left(p^{\prime}, p^{*}\right)=p^{\prime} \cdot q_{s}^{j}\left(p^{\prime}, p^{*}\right)
$$

\footnotetext{
${ }^{22}$ Given $p^{*}$, the upper bound of $p^{\prime}$ such that $q_{s}^{j}\left(p^{* *}\right) \geq 0$ is larger than that such that $q_{w}^{j}\left(p^{\prime *}\right) \geq 0$ if and only if $\alpha_{s}>\left(\beta_{w}-\gamma_{w}\right)\left(2 \beta_{s}-\gamma_{s}\right) \alpha_{w} /\left(\left(\beta_{s}-\gamma_{s}\right)\left(2 \beta_{w}-\gamma_{w}\right)\right)$. That is, for any $p^{\prime}$ such that $q_{w}^{j}\left(p^{\prime *}\right) \geq 0$, $q_{s}^{j}\left(p^{\prime *}\right) \geq 0$. In other words, given $p^{*}$, the strong market opens if the weak market does. The upper bound of $p^{\prime}$ such that $q_{s}^{j}\left(p^{* *}\right) \geq 0$ is $\left(\beta_{s}-\gamma_{s}\right) \alpha_{s}+\gamma_{s} p^{*}$. The upper bound of $p^{\prime}$ such that $q_{w}^{j}\left(p^{\prime *}\right) \geq 0$ is
} 


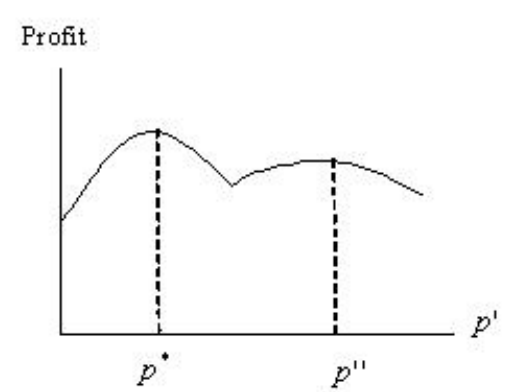

(1)

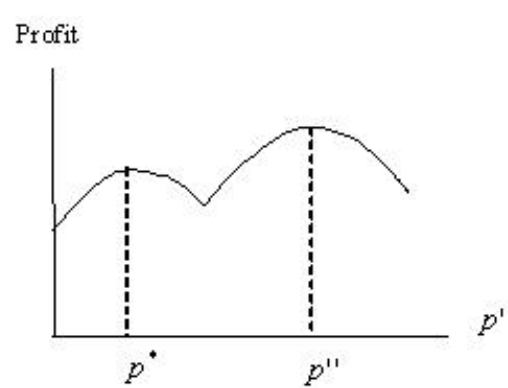

(2)

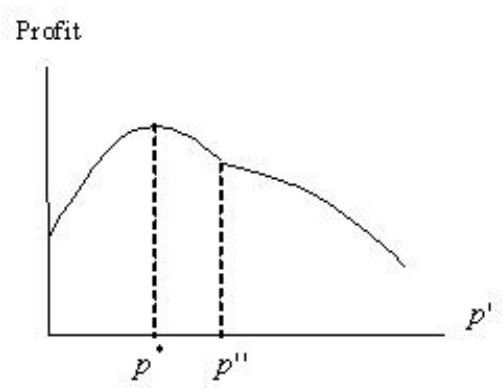

(3)

Figure 4: Profit when Deviating from the Equilibrium Price under Uniform Pricing

where

$$
q_{s}^{j}\left(p^{\prime}, p^{*}\right)=\frac{\alpha_{s}}{\beta_{s}+\gamma_{s}}-\frac{\beta_{s}}{\beta_{s}^{2}-\gamma_{s}^{2}} p^{\prime}+\frac{\gamma_{s}}{\beta_{s}^{2}-\gamma_{s}^{2}} p^{*} .
$$

Now, it is verified that

$$
\arg \max _{p^{\prime} \neq p^{*}} \tilde{\pi}\left(p^{*}\right)=\frac{\alpha_{s}\left(\beta_{s}-\gamma_{s}\right)}{2}+\frac{\gamma_{s}}{2} p^{*}\left(\equiv p^{\prime \prime}\right) .
$$

Note that firm $j$ 's profit function when it deviates to any price other than the equilibrium price would not necessarily be (globally) concave because it would be kinked at the threshold price where the weak market closes, as depicted in Figure 4.

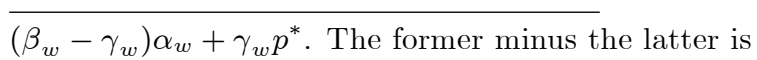

$$
\frac{\left[\left(\beta_{s}-\gamma_{s}\right)\left(2 \beta_{w}-\gamma_{w}\right) \alpha_{s}-\left(\beta_{w}-\gamma_{w}\right)\left(2 \beta_{s}-\gamma_{s}\right) \alpha_{w}\right]\left(\beta_{s}\left(\beta_{w}^{2}-\gamma_{w}^{2}\right)+\beta_{w}\left(\beta_{s}^{2}-\gamma_{s}^{2}\right)\right)}{\beta_{s} \beta_{w}\left(\left(\beta_{s}^{2}-\gamma_{s}^{2}\right)\left(2 \beta_{w}-\gamma_{w}\right)+\left(\beta_{w}^{2}-\gamma_{w}^{2}\right)\left(2 \beta_{s}-\gamma_{s}\right)\right)}>0 .
$$


If $p^{\prime \prime}$ attains the local maximum as in Panels (1) and (2) in Figure 4, then one needs to solve for the restriction on the set of parameters guaranteeing that the equilibrium profit when both markets are open

$$
p^{*}\left(\frac{\alpha_{s}-p^{*}}{\beta_{s}+\gamma_{s}}+\frac{\alpha_{w}-p^{*}}{\beta_{w}+\gamma_{w}}\right)
$$

is no smaller than the maximized profit when firm $j$ deviates to close the weak market

$$
\max _{p^{\prime} \neq p^{*}} \tilde{\pi}\left(p^{*}\right)
$$

It is, however, too complicated to obtain the set of parameters from this inequality. Thus, we instead focus on the case that corresponds to Panel (3) in Figure 4. This gives a sufficient condition for the weak market to open. Notice that by definition, $p^{\prime \prime}$ must satisfy $q_{w}^{j}\left(p^{\prime \prime}, p^{*}\right) \leq 0$, given $p^{*}$. If this is violated, then it is the case of Panel (3) in Figure 4. It shortens to

$$
\alpha_{w}>\frac{\left(\beta_{s}-\gamma_{s}\right)\left[2\left(\beta_{w}-\gamma_{w}\right)\left(\beta_{w}^{2}-\gamma_{w}^{2}\right) \beta_{s}+\left(2 \beta_{w}-\gamma_{w}\right)\left(\beta_{s}^{2}-\gamma_{s}^{2}\right) \beta_{w}\right]}{\left(\beta_{w}-\gamma_{w}\right)\left[2\left(2 \beta_{s}-\gamma_{s}\right)\left(\beta_{w}^{2}-\gamma_{w}^{2}\right) \beta_{s}+\left(4 \beta_{s}-\gamma_{s}\right)\left(\beta_{s}^{2}-\gamma_{s}^{2}\right) \beta_{w}\right]} \alpha_{s} .
$$

Together with the argument in Appendix A1, throughout the paper, we assume the relative size of the intercept of the weak market satisfies $\alpha_{w} / \alpha_{s} \in\left(\underline{\alpha_{w} / \alpha_{s}}, \overline{\alpha_{w} / \alpha_{s}}\right)$, where

$$
\begin{aligned}
\frac{\alpha_{w}}{\underline{\alpha_{s}}} & =\frac{\alpha_{w}}{\alpha_{s}}(\boldsymbol{\gamma}, \boldsymbol{\beta}) \\
& \equiv \frac{\left(\beta_{s}-\gamma_{s}\right)\left[2\left(\beta_{w}-\gamma_{w}\right)\left(\beta_{w}^{2}-\gamma_{w}^{2}\right) \beta_{s}+\left(2 \beta_{w}-\gamma_{w}\right)\left(\beta_{s}^{2}-\gamma_{s}^{2}\right) \beta_{w}\right]}{\left(\beta_{w}-\gamma_{w}\right)\left[2\left(2 \beta_{s}-\gamma_{s}\right)\left(\beta_{w}^{2}-\gamma_{w}^{2}\right) \beta_{s}+\left(4 \beta_{s}-\gamma_{s}\right)\left(\beta_{s}^{2}-\gamma_{s}^{2}\right) \beta_{w}\right]},
\end{aligned}
$$

and

$$
\begin{aligned}
\overline{\frac{\alpha_{w}}{\alpha_{s}}} & =\frac{\overline{\alpha_{w}}}{\alpha_{s}}(\boldsymbol{\gamma}, \boldsymbol{\beta}) \\
& \equiv \min \left[\frac{\left(\beta_{s}-\gamma_{s}\right)\left(2 \beta_{w}-\gamma_{w}\right)}{\left(\beta_{w}-\gamma_{w}\right)\left(2 \beta_{s}-\gamma_{s}\right)}, 1\right] .
\end{aligned}
$$

These restrictions are sufficient for markets $s$ and $w$ to be actually strong and weak and to be open under uniform pricing.

\section{A3. Proof of Proposition 1 (Calculating $\Delta S W^{*}$ as a Function of $p^{*}, p_{s}^{*}$ and $p_{w}^{*}$ )}

By using equations (A1-A5), we can calculate

$\Delta S W^{*}=\sum_{m \in\{s, w\}}\left[2 \alpha_{m}\left(q_{m}\left(p_{m}^{*}\right)-q_{m}\left(p^{*}\right)\right)-\left(\beta_{m}+\gamma_{m}\right)\left[q_{m}\left(p_{m}^{*}\right)-q_{m}\left(p^{*}\right)\right]\left[q_{m}\left(p_{m}^{*}\right)+q_{m}\left(p^{*}\right)\right]\right]$ 


$$
\begin{aligned}
& =\sum_{m \in\{s, w\}} \frac{\Delta p_{m}^{*}}{\beta_{m}+\gamma_{m}}\left[-2 \alpha_{m}+\left(\beta_{m}+\gamma_{m}\right)\left(q_{m}\left(p_{m}^{*}\right)+q_{m}\left(p^{*}\right)\right)\right] \\
& =\sum_{m \in\{s, w\}} \frac{\Delta p_{m}^{*}}{\beta_{m}+\gamma_{m}}\left[-2 \alpha_{m}+\left(\beta_{m}+\gamma_{m}\right)\left[\frac{\alpha_{m}\left(3 \beta_{m}-\gamma_{m}\right)}{\left(\beta_{m}+\gamma_{m}\right)\left(2 \beta_{m}-\gamma_{m}\right)}-\frac{p^{*}}{\beta_{m}+\gamma_{m}}\right]\right] \\
& =\sum_{m \in\{s, w\}} \frac{\Delta p_{m}^{*}}{\beta_{m}+\gamma_{m}}\left[-\frac{\alpha_{m}\left(\beta_{m}-\gamma_{m}\right)}{2 \beta_{m}-\gamma_{m}}-p^{*}\right] \\
& =-\sum_{m \in\{s, w\}} \frac{\Delta p_{m}^{*}}{\beta_{m}+\gamma_{m}}\left(p_{m}^{*}+p^{*}\right) .
\end{aligned}
$$

\section{A4. Proof of Proposition 2}

Using the explicit forms for $\Delta p_{m}^{*}$ and for $\Delta Q^{*}$ (derived in Appendix A1), we have

$$
\Delta Q^{*}=-2\left(\frac{\Delta p_{s}^{*}}{\beta_{s}+\gamma_{s}}+\frac{\Delta p_{w}^{*}}{\beta_{w}+\gamma_{w}}\right),
$$

which implies that $\Delta Q^{*} \leq 0$ if and only if

$$
\frac{\Delta p_{s}^{*}}{\beta_{s}+\gamma_{s}} \geq-\frac{\Delta p_{w}^{*}}{\beta_{w}+\gamma_{w}} .
$$

Now, suppose that $\Delta Q^{*}<0$. Then, we have

$$
\begin{aligned}
\Delta S W^{*} & =-\frac{\Delta p_{s}^{*}}{\beta_{s}+\gamma_{s}}\left(p_{s}^{*}+p^{*}\right)-\frac{\Delta p_{w}^{*}}{\beta_{w}+\gamma_{w}}\left(p_{w}^{*}+p^{*}\right) \\
& \leq-\frac{\Delta p_{s}^{*}}{\beta_{s}+\gamma_{s}}\left(p_{s}^{*}+p^{*}\right)+\frac{\Delta p_{s}^{*}}{\beta_{s}+\gamma_{s}}\left(p_{w}^{*}+p^{*}\right) \\
& =-\frac{\Delta p_{s}^{*}\left(p_{s}^{*}-p_{s}^{*}\right)}{\beta_{s}+\gamma_{s}}\left(p_{s}^{*}+p^{*}\right)<0 .
\end{aligned}
$$

\section{A5. Proof of Proposition 3}

We have

$$
\begin{aligned}
\Delta C S^{*}= & -\left\{\left(2 \beta_{s}-\gamma_{s}\right)^{2}\left(2 \beta_{w}-\gamma_{w}\right)^{2}\left[\left(\beta_{s}^{2}-\gamma_{s}^{2}\right)\left(2 \beta_{w}-\gamma_{w}\right)+\left(\beta_{w}^{2}-\gamma_{w}^{2}\right)\left(2 \beta_{s}-\gamma_{s}\right)\right]^{2}\right\}^{-1} \\
& \times\left[\alpha_{s}\left(\beta_{s}-\gamma_{s}\right)\left(2 \beta_{w}-\gamma_{w}\right)-\alpha_{w}\left(\beta_{w}-\gamma_{w}\right)\left(2 \beta_{s}-\gamma_{s}\right)\right] \\
& \times\left\{\alpha_{s}\left(\beta_{s}-\gamma_{s}\right)\left(2 \beta_{w}-\gamma_{w}\right)\right. \\
\quad & \times\left[\left(\beta_{s}^{2}-\gamma_{s}^{2}\right)\left(3 \beta_{s}-\gamma_{s}\right)\left(2 \beta_{w}-\gamma_{w}\right)^{2}\right. \\
\quad & \left.\quad\left(2 \beta_{s}-\gamma_{s}\right)\left(\beta_{w}^{2}-\gamma_{w}^{2}\right)\left(4 \beta_{s} \beta_{w}-4 \beta_{s} \gamma_{w}+2 \beta_{s} \beta_{w}-\gamma_{s} \beta_{w}+\gamma_{s} \gamma_{w}\right)\right]
\end{aligned}
$$




$$
\begin{aligned}
& -\alpha_{w}\left(2 \beta_{s}-\gamma_{s}\right)\left(\beta_{w}-\gamma_{w}\right) \\
& \times\left[\left(\beta_{s}^{2}-\gamma_{s}^{2}\right)\left(2 \beta_{w}-\gamma_{w}\right)\left(4 \beta_{s} \beta_{w}-4 \beta_{w} \gamma_{s}+2 \beta_{s} \beta_{w}-\gamma_{w} \beta_{s}+\gamma_{s} \gamma_{w}\right)\right. \\
& \left.\left.\quad+\left(2 \beta_{s}-\gamma_{s}\right)^{2}\left(\beta_{w}^{2}-\gamma_{w}^{2}\right)\left(3 \beta_{w}-\gamma_{w}\right)\right]\right\}
\end{aligned}
$$

which can be seen as an increasing function of $\alpha_{w}$.

Remember from Appendix A2 that

$$
\alpha_{w}<\min \left[\frac{\alpha_{s}\left(\beta_{s}-\gamma_{s}\right)\left(2 \beta_{w}-\gamma_{w}\right)}{\left(\beta_{w}-\gamma_{w}\right)\left(2 \beta_{s}-\gamma_{s}\right)}, \alpha_{s}\right],
$$

and it is verified that

$$
\min \left[\frac{\alpha_{s}\left(\beta_{s}-\gamma_{s}\right)\left(2 \beta_{w}-\gamma_{w}\right)}{\left(\beta_{w}-\gamma_{w}\right)\left(2 \beta_{s}-\gamma_{s}\right)}, \alpha_{s}\right]=\alpha_{s}
$$

if $-\gamma_{s} \beta_{w}+\beta_{s} \gamma_{w}>0$, and

$$
\min \left[\frac{\alpha_{s}\left(\beta_{s}-\gamma_{s}\right)\left(2 \beta_{w}-\gamma_{w}\right)}{\left(\beta_{w}-\gamma_{w}\right)\left(2 \beta_{s}-\gamma_{s}\right)}, \alpha_{s}\right]=\frac{\alpha_{s}\left(\beta_{s}-\gamma_{s}\right)\left(2 \beta_{w}-\gamma_{w}\right)}{\left(\beta_{w}-\gamma_{w}\right)\left(2 \beta_{s}-\gamma_{s}\right)}
$$

otherwise. Noting the continuity, we show below that $\Delta C S^{*}$ as an increasing function of $\alpha_{w}$ is negative for

$$
\alpha_{w}=\min \left[\frac{\alpha_{s}\left(\beta_{s}-\gamma_{s}\right)\left(2 \beta_{w}-\gamma_{w}\right)}{\left(\beta_{w}-\gamma_{w}\right)\left(2 \beta_{s}-\gamma_{s}\right)}, \alpha_{s}\right] .
$$

First, if $\alpha_{w}=\alpha_{s}$, then we have

$$
\begin{aligned}
\Delta C S^{*}=- & \left\{\left(2 \beta_{s}-\gamma_{s}\right)^{2}\left(2 \beta_{w}-\gamma_{w}\right)^{2}\left[\left(\beta_{s}^{2}-\gamma_{s}^{2}\right)\left(2 \beta_{w}-\gamma_{w}\right)+\left(\beta_{w}^{2}-\gamma_{w}^{2}\right)\left(2 \beta_{s}-\gamma_{s}\right)\right]^{2}\right\}^{-1} \\
& \times \alpha_{s}^{2}\left(-\gamma_{s} \beta_{w}+\beta_{s} \gamma_{w}\right) \\
& \times\left[\left(\beta_{s}^{2}-\gamma_{s}^{2}\right)\left(2 \beta_{w}-\gamma_{w}\right)\left(2 \beta_{s} \beta_{w}+\left(\beta_{s}-\gamma_{s}\right) \gamma_{w}\right)\right. \\
& \left.\quad+\left(\beta_{w}^{2}-\gamma_{w}^{2}\right)\left(2 \beta_{s}-\gamma_{s}\right)\left(2 \beta_{s} \beta_{w}+\left(\beta_{w}-\gamma_{w}\right) \gamma_{s}\right)\right]
\end{aligned}
$$

which is negative because $-\gamma_{s} \beta_{w}+\beta_{s} \gamma_{w}>0$. On the other hand, if

$$
\alpha_{w}=\frac{\alpha_{s}\left(\beta_{s}-\gamma_{s}\right)\left(2 \beta_{w}-\gamma_{w}\right)}{\left(\beta_{w}-\gamma_{w}\right)\left(2 \beta_{s}-\gamma_{s}\right)}
$$

then the term in the expression of $\Delta C S^{*}$,

$$
\begin{aligned}
& \left\{\alpha_{s}\left(\beta_{s}-\gamma_{s}\right)\left(2 \beta_{w}-\gamma_{w}\right)\right. \\
& \times\left[\left(\beta_{s}^{2}-\gamma_{s}^{2}\right)\left(3 \beta_{s}-\gamma_{s}\right)\left(2 \beta_{w}-\gamma_{w}\right)^{2}\right.
\end{aligned}
$$




\begin{tabular}{c|cccc}
\hline \hline & $\left(\gamma, \beta_{s}, \beta_{w}\right)=$ & & \\
& & & & \\
& $(0.3,1.0,0.75)$ & $(0.3,0.75,1.0)$ & $(-0.3,1.0,0.75)$ & $(-0.3,0.75,1.0)$ \\
\hline$p^{*}$ & 0.3582 & 0.3644 & 0.5235 & 0.5423 \\
$p_{s}^{*}\left(\Delta p_{s}^{*} / p^{*}\right)$ & $0.4118(15 \%)$ & $0.3750(3 \%)$ & $0.5652(8 \%)$ & $0.5833(8 \%)$ \\
$p_{w}^{*}\left(\Delta p_{w}^{*} / p^{*}\right)$ & $0.3188(-11 \%)$ & $0.3500(-4 \%)$ & $0.4958(-5 \%)$ & $0.4804(-11 \%)$ \\
$\Delta q_{s}^{*}\left(\Delta q_{s}^{*} / q_{s}^{*}\left(p^{*}\right)\right)$ & $-0.9412(-8 \%)$ & $-0.0101(-2 \%)$ & $-0.0596(-9 \%)$ & $-0.0912(-9 \%)$ \\
$\Delta q_{w}^{*}\left(\Delta q_{w}^{*} / q_{w}^{*}\left(p^{*}\right)\right)$ & $0.0375(8 \%)$ & $0.0111(3 \%)$ & $0.0615(8 \%)$ & $0.0884(20 \%)$ \\
\hline$\Delta S W^{*}$ & -0.0063 & 0.0005 & -0.0022 & -0.0123 \\
$\Delta C S_{s}^{*}$ & -0.0507 & -0.0127 & -0.0543 & -0.0797 \\
$\Delta C S_{w}^{*}$ & 0.0384 & 0.0109 & 0.0419 & 0.0598 \\
$\Delta \Pi^{*}$ & 0.0060 & 0.0023 & 0.0102 & 0.0076 \\
\hline$\Delta Q^{*}$ & -0.0037 & 0.0009 & 0.0019 & -0.0028 \\
\hline \hline
\end{tabular}

Table 2: Substitutability versus Complementarity with $\beta_{s} \neq \beta_{w}\left(\alpha_{w}=0.85\right)$

$$
\begin{aligned}
& \left.+\left(2 \beta_{s}-\gamma_{s}\right)\left(\beta_{w}^{2}-\gamma_{w}^{2}\right)\left(4 \beta_{s} \beta_{w}-4 \beta_{s} \gamma_{w}+2 \beta_{s} \beta_{w}-\gamma_{s} \beta_{w}+\gamma_{s} \gamma_{w}\right)\right] \\
& -\alpha_{w}\left(2 \beta_{s}-\gamma_{s}\right)\left(\beta_{w}-\gamma_{w}\right) \\
& \times\left[\left(\beta_{s}^{2}-\gamma_{s}^{2}\right)\left(2 \beta_{w}-\gamma_{w}\right)\left(4 \beta_{s} \beta_{w}-4 \beta_{w} \gamma_{s}+2 \beta_{s} \beta_{w}-\gamma_{w} \beta_{s}+\gamma_{s} \gamma_{w}\right)\right. \\
& \left.\left.+\left(2 \beta_{s}-\gamma_{s}\right)^{2}\left(\beta_{w}^{2}-\gamma_{w}^{2}\right)\left(3 \beta_{w}-\gamma_{w}\right)\right]\right\}
\end{aligned}
$$

is simplified to

$$
\begin{aligned}
& 2 \alpha_{s}\left(\beta_{s}-\gamma_{s}\right)\left(2 \beta_{w}-\gamma_{w}\right)\left(\gamma_{s} \beta_{w}-\beta_{s} \gamma_{w}\right) \\
& \times\left[\left(\beta_{s}^{2}-\gamma_{s}^{2}\right)\left(2 \beta_{w}-\gamma_{w}\right)+\left(\beta_{w}^{2}-\gamma_{w}^{2}\right)\left(2 \beta_{s}-\gamma_{s}\right)\right],
\end{aligned}
$$

which is positive because $\gamma_{s} \beta_{w}-\beta_{s} \gamma_{w}>0$, which implies that $\Delta C S^{*}<0$ in this case.

\section{A6. Welfare Analysis when $\gamma_{m}$ is Common}

Let $\gamma \equiv \gamma_{s}=\gamma_{w}$. We allow $\beta_{s}$ and $\beta_{w}$ to differ and provide numerical analysis to contrast substitutability with complementarity for a fixed value of $\left(\alpha_{w}, \beta_{s}, \beta_{w}\right)$, and graphical arguments on the domains $\left(\beta_{s}, \beta_{w}\right)$ for $\Delta S W^{*}>0$, with the value of $\left(\gamma, \alpha_{w}\right)$ fixed.

Table 2 shows the result for the case of $\alpha_{w}=0.85$. The first and the second column corresponds to the case of substitutability $(\gamma=0.3)$, while the third and the fourth correspond to the case of complementarity $(\gamma=-0.3)$. The difference between the first and the second (the third and the fourth in the case of complementarity) columns is 
whether the own slope of the inverse demand curve in the strong market is greater than that in the weak market (i.e., $\beta_{s}>\beta_{w}$ ). Notice that price discrimination improves social welfare only in the second case $\left(\left(\gamma, \beta_{s}, \beta_{w}\right)=(0.3,0.75,1.0)\right)$. In this case, $\left|\Delta q_{s}^{*}\right| / q_{s}^{*}\left(p^{*}\right)$ is particularly small $(2 \%)$, while $\Delta q_{w}^{*} / q_{w}^{*}\left(p^{*}\right)$, is also not too large $(3 \%)$, in comparison with the other three cases.

First, consider the case of substitutable goods $(\gamma>0)$. Notice that when $\beta_{s}>\beta_{w}$, the strong market has a higher value of price elasticity than the weak market (see equation (4)). The equilibrium price in the strong market $p_{s}^{*}$, however, is at a higher level than in the case of $\beta_{s}<\beta_{w}$ (0.4118 vs. 0.3750$)$. This seemingly paradoxical result is due to strategic effects: the firms want to "cooperate" because they are afraid of retaliation when the market is more price elastic. Now, if the market is "integrated" (i.e., uniform pricing is forced), then the market price in the strong market is expected to drop to a larger extent than in the case of $\beta_{s}<\beta_{w}$, because the strong market has a higher value of price elasticity (it is more competitive) than the weak market when $\beta_{s}>\beta_{w}$. In Table 2, we see the price in the strong market drop from 0.4118 to $0.3582(-6 \%)$ when $\left(\gamma, \beta_{s}, \beta_{w}\right)=(0.3,1,0.75)$, while $p_{s}$ drops from 0.3750 to $0.3644(-3 \%)$ when $\left(\gamma, \beta_{s}, \beta_{w}\right)=(0.3,0.75,1.0)$. To summarize, when the strong market is less price elastic, the regime of uniform pricing does not lower the price in the strong market sufficiently. As a result, uniform pricing may harm social welfare. In other words, price discrimination may improve welfare.

Even though the products are complements, a similar logic can apply to the property of price discrimination. When the products are complements, the price changes and the associated production changes are large due to the greater elasticity created by complementarity. In fact, welfare loss is larger in the fourth case (where the strong market has a higher value of price elasticity than the weak market does) than in the third case $(\mid-0.0123]>|-0.0022|)$. As to the changes in equilibrium aggregate output, it is positive in our second and third cases but negative in the other two. These results are consistent with Proposition 2: an increase in the aggregate output is necessary for welfare to be improved by price discrimination, as in the case of monopoly.

The difference between substitutability and complementarity is further investigated graphically. Figures 5 and 6 depict the region of $\Delta S W^{*}>0$ for the cases of substitutability 


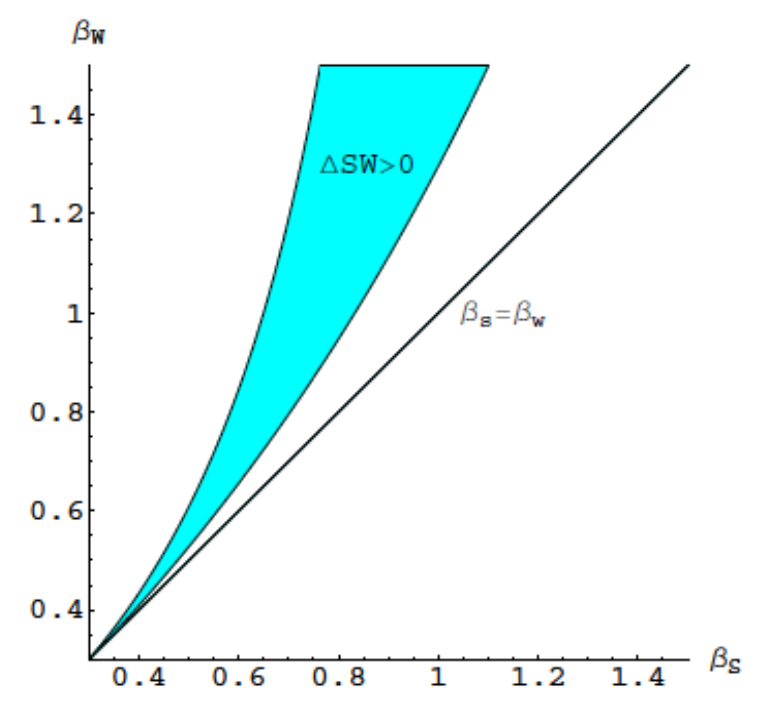

Figure 5: Substitutability $(\gamma=0.3)$ in the Case of $\alpha_{w}=0.85$

$(\gamma=0.3)$ and of complementarity $(\gamma=-0.3)$, respectively (with $\left.\alpha_{w}=0.85\right)$. Notice that $\left(\beta_{s}, \beta_{w}\right)=(0.75,1.0)$ in Table 2 is contained in the shaded region of Figure 5 . The result for the case of substitutability is expected from the argument above. For the case of complementarity, the combination of "high $\beta_{s}$ and low $\beta_{w}$ " works for welfare improvement, the reverse of the situation in the case of substitutability. Notice that complementarity makes the demand in each market more price elastic. With elasticity already sufficienty high, a higher value of $\beta_{s}$ raises the uniform price, and thus the price change introduced by price discrimination is reduced because of the high value of $\beta_{s}$, reducing the inefficiency of price discrimination in the strong market.

In Figure 5, the white area around the top right corner violates the condition that $\alpha_{s} / \alpha_{w}>\underline{\alpha_{s} / \alpha_{w}}$. The violation means that the discriminatory price in the strong market with $\alpha_{s}$ is lower than that in the weak market with $\alpha_{w}$ (note that $\alpha_{s}>\alpha_{w}$ ). In other words, the discriminatory price at the market with a higher intercept $\left(\alpha_{s}\right)$ is lower than that in the market with a lower intercept $\left(\alpha_{w}\right)$. Following the definition of a "strong" market in Section 2, we now redefine the former as the "weak market" and the latter as the "strong' market." On this white area where $\beta_{s}<\beta_{w}$ holds, the redefined "weak" market with a higher intercept is more elastic than the redefined "strong" market with a lower intercept. As mentioned above, when the "weak" market is elastic, the increase 


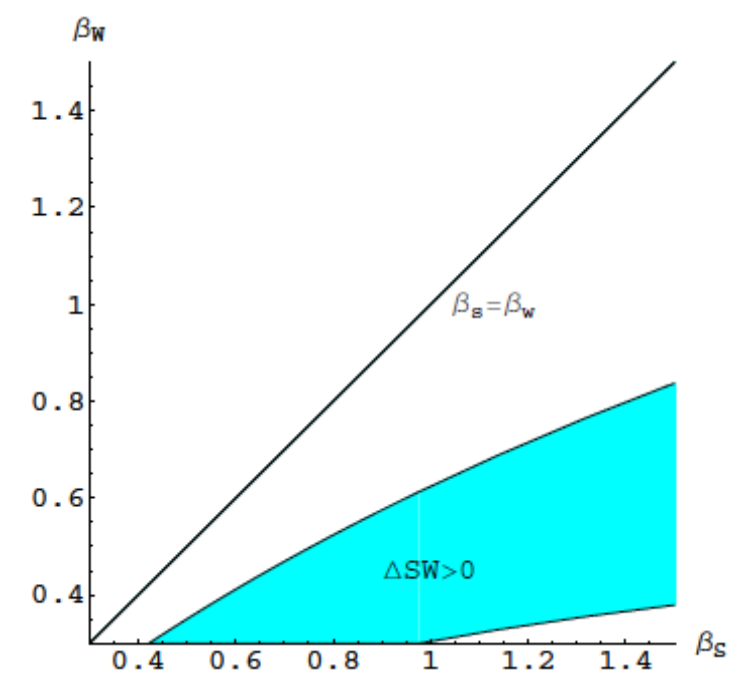

Figure 6: Complementarity $(\gamma=-0.3)$ in the Case of $\alpha_{w}=0.85$

in quantity in the weak market is not high enough to offset the loss from the decrease in quantity in the strong market; that is, $\Delta Q<0$. In fact, in this white area, price discrimination deteriorates the total social surplus.

Lastly, it is verified that consumer surplus is never improved by price discrimination in the cases of $\left(\gamma, \alpha_{w}\right)=(0.3,0.85)$ and of $\left(\gamma, \alpha_{w}\right)=(-0.3,0.85)$. Thus, this and other numeral results suggest that welfare improvement from price discrimination is solely due to an increase in the firms' profits. In particular, it means that there is little or no chance that firms will suffer from "prisoners' dilemma"; that is, firms are mostly or always better by switching from uniform pricing to price discrimination.

\section{A7. Proof of Proposition 6}

Substituting $\bar{\gamma}_{s}$ into $\partial \Delta S W^{*} / \partial \gamma_{s}$, we have

$$
\left.\frac{\partial \Delta S W^{*}}{\partial \gamma_{s}}\right|_{\gamma_{s}=\bar{\gamma}_{s}}=-\frac{2\left(\alpha_{s}-\alpha_{w}\right) \alpha_{w}\left(\beta_{w}-\gamma_{w}\right)\left[\alpha_{s} \beta_{w}+\left(\alpha_{s}-\alpha_{w}\right)\left(\beta_{w}-\gamma_{w}\right)\right]^{3}}{\alpha_{s} \beta_{s}\left(2 \beta_{w}-\gamma_{w}\right)^{3} M}
$$

where

$$
\begin{aligned}
M= & \left(2 \beta_{w}-\gamma_{w}\right)\left(\beta_{w}+\gamma_{w}\right) \alpha_{s}^{2} \\
& +\alpha_{s} \alpha_{w}\left\{2 \beta_{s}\left(2 \beta_{w}-\gamma_{w}\right)-\left(\beta_{w}-\gamma_{w}\right)\left(\beta_{w}+\gamma_{w}\right)\right\}-3 \beta_{s} \alpha_{w}^{2}\left(\beta_{w}-\gamma_{w}\right)
\end{aligned}
$$


Notice that $\alpha_{s}>\alpha_{w}, \beta_{w}>\gamma_{w}, \alpha_{s} \beta_{w}+\left(\alpha_{s}-\alpha_{w}\right)\left(\beta_{w}-\gamma_{w}\right)>0$, and $2 \beta_{w}-\gamma_{w}$. It can be shown that $M$ is a concave function of $\alpha_{w}$. For $\alpha_{w} \in\left[0, \alpha_{s}\right]$, this function is locally maximized at $\alpha_{w}=0$ or $\alpha_{w}=\alpha_{s}$. When $\alpha_{w}=0, M=\left(2 \beta_{w}-\gamma_{w}\right)\left(\beta_{w}+\gamma_{w}\right) \alpha_{s}^{2}>0$. When $\alpha_{w}=\alpha_{s}, M=\alpha_{s}^{2}\left(\beta_{s}+\beta_{w}\right)\left(\beta_{w}+\gamma_{w}\right)>0$. Therefore,

$$
\left.\frac{\partial \Delta S W^{*}}{\partial \gamma_{s}}\right|_{\gamma_{s}=\bar{\gamma}_{s}}<0 .
$$

Thus, there exists $\gamma_{s}^{\prime}$ such that $\Delta S W^{*}>0$ for $\gamma_{s} \in\left(\gamma_{s}^{\prime}, \bar{\gamma}_{s}\right)$.

\section{References}

[1] Adachi, Takanori. 2002. "A Note on 'Third-Degree Price Discrimination with Interdependent Demands'." Journal of Industrial Economics 50 (2), 235.

[2] —. 2005. "Third-Degree Price Discrimination, Consumption Externalities and Social Welfare." Economica 72 (1), 171-178.

[3] Aguirre, Iñaki, Simon Cowan, and John Vickers. 2010. "Monopoly Price Discrimination and Demand Curvature." American Economic Review, 100 (4), 16011615 .

[4] Armstrong, Mark. 2006. "Recent Developments in the Economics of Price Discrimination." in Richard Blundell, Whitney K. Newey, and (eds.) Advances in Economics and Econometrics, 9th World Congress: Theory and Applications, Volume 2, Cambridge University Press.

[5] Belleflamme, Paul, and Martin Peitz. 2010. Industrial Organization: Markets and Strategies. Cambridge University Press.

[6] Bertoletti, Paolo. 2004. "A Note on Third-Degree Price Discrimination and Output." Journal of Industrial Economics 52 (3), 457.

[7] Corts, Kenneth S. 1998. "Third-Degree Price Discrimination in Oligopoly: AllOut Competition and Strategic Commitment." RAND Journal of Economics 29 (2), 306-323. 
[8] Cowan, Simon. 2007. "The Welfare Effects of Third-Degree Price Discrimination with Nonlinear Demand Functions." RAND Journal of Economics 38 (2), 419-428.

[9] Dastidar, Krishnendu Ghosh. 2006. "On Third-Degree Price Discrimination in Oligopoly." The Manchester School 74 (2), 231-250.

[10] Galera, Francisco, and Jesús M. Zaratieguia. 2006. "Welfare and Output in Third-Degree Price Discrimination: A Note." International Journal of Industrial Organization 24 (3), 605-611.

[11] Hausman, Jerry A., and Jeffrey K. MacKie-Mason. 1988. "Price Discrimination and Patent Policy." RAND Journal of Economics 19 (2), 253-265.

[12] Holmes, Thomas J. 1989. "The Effects of Third-Degree Price Discrimination in Oligopoly." American Economic Review 79 (1), 244-250.

[13] Ikeda, Takeshi, and Tatsuhiko Nariu. 2009. "Third-Degree Price Discrimination in the Presence of Asymmetric Consumption Externalities." Journal of Industry, Competition and Trade 9 (3), 251-261.

[14] —, And Tsuyoshi Toshimitsu. 2010. "Third-Degree Price Discrimination, Quality Choice, and Welfare." Economics Letters 106 (1), 54-56.

[15] Layson, Stephen K. 1998. "Third-Degree Price Discrimination with Interdependent Demands." Journal of Industrial Economics 46 (4), 511-524.

[16] Pigou, Arthur C. 1920. The Economics of Welfare. London: Macmillan.

[17] Robinson, Joan. 1933. The Economics of Imperfect Competition. London: Macmillan.

[18] Schmalensee, Richard. 1981. "Output and Welfare Implications of monopolistic Third-Degree Price Discrimination." American Economic Review 71 (2), 242-247.

[19] Schwartz, Marius. 1990. "Third-Degree Price Discrimination ant Output: Generalizing a Welfare Result." American Economic Review 80 (5), 1259-1262. 
[20] Shy, Oz. 2008. How to Price: A Guide to Pricing Techniques and Yield Management. Cambridge University Press.

[21] Stole, Lars. 2007. "Price Discrimination and Competition." in Mark Armstrong and Robert H. Porter (eds), Handbook of Industrial Organization, Volume III, Elsevier Science Publishers B.V.

[22] Varian, Hal R. 1985. "Price Discrimination and Social Welfare." American Economic Review $\mathbf{7 5}$ (4), 870-875.

[23] Vives, Xavier. 1999. Oligopoly Pricing: Old Ideas and New Tools. The MIT Press. 